\title{
Opposition-based differential evolution for hydrothermal power system
}

\author{
Jagat Kishore Pattanaik ${ }^{*}$ (D) Mousumi Basu ${ }^{1}$ and Deba Prasad Dash ${ }^{2}$
}

\begin{abstract}
This paper presents opposition-based differential evolution to determine the optimal hourly schedule of power generation in a hydrothermal system. Differential evolution (DE) is a population-based stochastic parallel search evolutionary algorithm. Opposition-based differential evolution has been used here to improve the effectiveness and quality of the solution. The proposed opposition-based differential evolution (ODE) employs opposition-based learning (OBL) for population initialization and also for generation jumping. The effectiveness of the proposed method has been verified on two test problems, two fixed head hydrothermal test systems and three hydrothermal multi-reservoir cascaded hydroelectric test systems having prohibited operating zones and thermal units with valve point loading. The results of the proposed approach are compared with those obtained by other evolutionary methods. It is found that the proposed opposition-based differential evolution based approach is able to provide better solution.
\end{abstract}

Keywords: Differential evolution, Opposition-based differential evolution, Hydrothermal system, Fixed head, Variable head

\section{Introduction}

Optimal scheduling of power plant generation is of great importance to electric utility systems. Because of insignificant marginal cost of hydroelectric power, the problem of minimizing the operational cost of hydrothermal system essentially reduces to that of minimizing the fuel cost of thermal plants under the various constraints on the hydraulic, thermal and power system network.

The hydrothermal scheduling problem has been the subject of investigation for several decades. Several classical methods such as Newton's method [1], mixed integer programming [2, 3], dynamic programming (DP) [4], etc. have been widely used to solve hydrothermal scheduling problem. Among these methods, DP appears to be the most popular. However, major disadvantages of DP method are computational and dimensional requirements which grow drastically with increasing system size and planning horizon.

Recently, stochastic search algorithms such as simulated annealing (SA) [5], evolutionary programming (EP)

\footnotetext{
* Correspondence: jagat.ju@gmail.com

1 Department of Power Engineering, Jadavpur University, Salt Lake City, Kolkata 700098 , India

Full list of author information is available at the end of the article
}

[6], genetic algorithm (GA) [7, 8], evolutionary programming technique [9], differential evolution (DE) [10-12], particle swarm optimization [13], artificial immune system [14], clonal selection algorithm [15] and teaching learning based optimization [16] have been successfully used to solve hydrothermal scheduling problem.

Since the mid 1990s, many techniques originated from Darwin's natural evolution theory have emerged. These techniques are usually termed by "evolutionary computation methods" including evolutionary algorithms (EAs), swarm intelligence and artificial immune system. Differential evolution (DE) [17-20], a relatively new member in the family of evolutionary algorithms, first proposed over 1995-1997 by Storn and Price at Berkeley is a novel approach to numerical optimization. It is a population-based stochastic parallel search evolutionary algorithm which is very simple yet powerful. The main advantages of $\mathrm{DE}$ are its capability of solving optimization problems which require minimization process with nonlinear, nondifferentiable and multi-modal objective functions.

The basic concept of opposition-based learning (OBL) [21-23] was originally introduced by Tizhoosh. The 
main idea behind OBL is for finding a better candidate solution and the simultaneous consideration of an estimate and its corresponding opposite estimate (i.e., guess and opposite guess) which is closer to the global optimum. OBL was first utilized to improve learning and back propagation in neural networks by Ventresca and Tizhoosh [24], and since then, it has been applied to many EAs, such as differential evolution [25], particle swarm optimization [26] and ant colony optimization [27].

Opposition-based harmony search algorithm [28] has been applied to solve combined economic and emission dispatch problems. In [29] oppositional real coded chemical reaction optimization has been used for solving economic dispatch problems. Opposition-based gravitational search algorithm [30] has been applied for solving reactive power dispatch problem.

This paper proposes opposition-based differential evolution (ODE) for optimal scheduling of generation in a hydrothermal system. This paper considers fixed head as well as variable head hydrothermal system. In case of fixed head hydro plants, water discharge rate curves are modeled as a quadratic function of the hydropower generation and thermal units with nonsmooth fuel cost function. Here, scheduling period is divided into a number of subintervals each having a constant load demand. In case of variable head hydrothermal system, multi-reservoir cascaded hydro plants having prohibited operating zones and thermal units with valve point loading are used. The proposed method is validated by applying it to two test problems, two fixed head hydrothermal test systems and three hydrothermal multi-reservoir cascaded hydroelectric test systems having prohibited operating zones and thermal units with valve point loading. The test results are compared with those obtained by other evolutionary methods reported in the literature. From numerical results, it is found that the proposed ODE based approach provides better solution.

\section{Problem formulation}

\section{Fixed head hydrothermal system}

Fixed head hydrothermal scheduling problem with $N_{h}$ hydro units and $N_{s}$ thermal units over $M$ time subintervals is described as follows:

\section{Objective function}

The fuel cost function of each thermal generator, considering valve-point effect, is expressed as a sum of quadratic and sinusoidal function. The superimposed sine components represent rippling effect produced by steam admission valve opening. The problem minimizes following total fuel cost

$$
\begin{aligned}
& f_{F H}=\sum_{m=1}^{\mathrm{M}} \sum_{i=1}^{\mathrm{N}_{s}} t_{m}\left[a_{s i}+b_{s i} \mathrm{P}_{s i m}+c_{s i} \mathrm{P}_{s i m}^{2}+\right. \\
& \left.d_{s i} \times \sin \left\{e_{s i} \times\left(\mathrm{P}_{s i}^{\mathrm{min}}-\mathrm{P}_{s i m}\right)\right\}\right]
\end{aligned}
$$

\section{Constraints}

(i) Power balance constraints:

$$
\sum_{i=1}^{\mathrm{N}_{s}} \mathrm{P}_{s i m}+\sum_{j=1}^{\mathrm{N}_{h}} \mathrm{P}_{h j m}-\mathrm{P}_{D m}-\mathrm{P}_{L m}=0 \quad m \in \mathrm{M}
$$

and

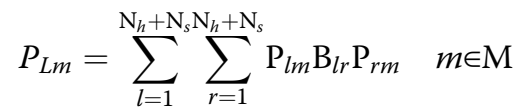

(ii) Water availability constraints:

$$
\sum_{m=1}^{\mathrm{M}}\left[t_{m}\left(a_{0 h j}+a_{1 h j} \mathrm{P}_{h j m}+a_{2 h j} \mathrm{P}_{h j m}^{2}\right)\right]-W_{h j}=0 \quad j \in \mathrm{N}_{h}
$$

(iii) Generation limits:

$$
\mathrm{P}_{h j}^{\min } \leq \mathrm{P}_{h j m} \leq \mathrm{P}_{h j}^{\max } \quad j \in \mathrm{N}_{h}, \quad m \in \mathrm{M}
$$

and

$$
\mathrm{P}_{s i}^{\min } \leq \mathrm{P}_{s i m} \leq \mathrm{P}_{s i}^{\max } \quad i \in \mathrm{N}_{s}, \quad m \in \mathrm{M}
$$

\section{Determination of generation level of slack generator}

Thermal generators and hydro generators deliver their power output subject to the power balance constraint (2), water availability constraint (4) and respective capacity constraints (5) and (6). Assuming the power loading of $N_{P}$ and first $\left(N_{s}-1\right)$ generators are known, the power level of the $N_{s}$ th generator (i.e. the slack generator) is given by

$$
\mathrm{P}_{\mathrm{N}_{s} m}=\mathrm{P}_{D m}+\mathrm{P}_{L m}-\sum_{l=1}^{\mathrm{N}_{h}+\mathrm{N}_{s}-1} \mathrm{P}_{l m} \quad m \in \mathrm{M}
$$

The transmission loss $P_{L m}$ is a function of all the generators including the slack generator and it is given by

$$
\begin{aligned}
\mathrm{P}_{L m}= & \sum_{l=1}^{\mathrm{N}_{h}+\mathrm{N}_{s}-1 \mathrm{~N}_{h}+\mathrm{N}_{s}-1} \sum_{r=1}^{\mathrm{N}_{h}+\mathrm{N}_{s}-1} \mathrm{P}_{l m} \mathrm{~B}_{l r} \mathrm{P}_{r m} \\
& +2 \mathrm{P}_{\mathrm{N}_{s} m}\left(\sum_{l=1}^{\mathrm{N}^{\prime}} \mathrm{B}_{\mathrm{N}_{s} l} \mathrm{P}_{l m}\right) \\
& +\mathrm{B}_{\mathrm{N}_{s} \mathrm{~N}_{s}} \mathrm{P}_{\mathrm{N}_{s} m}^{2} \quad m \in \mathrm{M}
\end{aligned}
$$

Expanding and rearranging, equation (7) becomes 


$$
\begin{aligned}
& \mathrm{B}_{\mathrm{N}_{s} \mathrm{~N}_{s}} \mathrm{P}_{\mathrm{N}_{s} m}^{2}+\left(2 \sum_{l=1}^{\mathrm{N}_{h}+\mathrm{N}_{s}-1} \mathrm{~B}_{\mathrm{N}_{s} l} \mathrm{P}_{l m}-1\right) \mathrm{P}_{\mathrm{N}_{s} m}+P_{D m} \\
& +\sum_{l=1}^{\mathrm{N}_{h}+\mathrm{N}_{s}-1 \mathrm{~N}_{h}+\mathrm{N}_{s}-1} \sum_{\substack{r=1 \\
m \in \mathrm{M}}} \mathrm{P}_{l m} \mathrm{~B}_{l r} \mathrm{P}_{r m}-\sum_{l=1}^{\mathrm{N}_{h}+\mathrm{N}_{s}-1} \mathrm{P}_{l m} \\
& =0
\end{aligned}
$$

The loading of the slack generator (i.e. $N_{s}$ th) can then be found by solving equation (9) using standard algebraic method.

\section{Variable head hydrothermal system}

The variable head hydrothermal scheduling problem is aimed to minimize the fuel cost of thermal plants, while making use of the availability of hydro power as much as possible. The objective function and associated constraints of the hydrothermal scheduling problem are formulated as follows.

\section{Objective function}

$$
\text { Minimize } \begin{aligned}
f_{V H}= & \sum_{t=1}^{\mathrm{T}} \sum_{i=1}^{\mathrm{N}_{s}}\left[a_{s i}+b_{s i} \mathrm{P}_{s i t}+c_{s i} \mathrm{P}_{s i t}^{2}\right. \\
& \left.+\left|d_{s i} \times \sin \left\{e_{s i} \times\left(\mathrm{P}_{s i}^{\mathrm{min}}-\mathrm{P}_{s i t}\right)\right\}\right|\right]
\end{aligned}
$$

\section{Constraints}

(i) Power balance constraints:

The total active power generation must balance the predicted power demand and transmission loss, at each time interval over the scheduling horizon

$$
\sum_{i=1}^{\mathrm{N}_{s}} P_{s i t}+\sum_{j=1}^{\mathrm{N}_{h}} \mathrm{P}_{h j t}-\mathrm{P}_{D t}-\mathrm{P}_{L t}=0 \quad t \in \mathrm{T}
$$

The hydroelectric generation is a function of water discharge rate and reservoir water head, which in turn, is a function of storage.

$$
\begin{aligned}
\mathrm{P}_{h j t}= & C_{1 j} V_{h j t}^{2}+C_{2 j} Q_{h j t}^{2}+C_{3 j} V_{h j t} Q_{h j t} \\
& +C_{4} V_{h j t}+C_{5 j} Q_{h j t} \\
& +C_{6 j} \quad j \in \mathrm{N}_{h} \quad t \in \mathrm{T}
\end{aligned}
$$

The transmission loss $P_{L t}$ is given by

$$
P_{L t}=\sum_{i=1}^{\mathrm{N}_{s}+\mathrm{N}_{h} \mathrm{~N}_{s}+\mathrm{N}_{h}} \sum_{j=1} \mathrm{P}_{i t} \mathrm{~B}_{i j} \mathrm{P}_{j t}+\sum_{i=1}^{\mathrm{N}_{s}+\mathrm{N}_{h}} \mathrm{~B}_{0 i} \mathrm{P}_{i t}+\mathrm{B}_{00}
$$

(ii) Generation limits:

$$
\mathrm{P}_{h j}^{\min } \leq \mathrm{P}_{h j t} \leq \mathrm{P}_{h j}^{\max }, \quad j \in \mathrm{N}_{h}, \quad \mathrm{t} \in T
$$

and

$$
\mathrm{P}_{s i}^{\min } \leq \mathrm{P}_{s i t} \leq \mathrm{P}_{s i}^{\max }, \quad i \in \mathrm{N}_{s}, \quad t \in \mathrm{T}
$$

(iii) Hydraulic network constraints

The hydraulic operational constraints comprise the water balance equations for each hydro unit as well as the bounds on reservoir storage and release targets. These bounds are determined by the physical reservoir and plant limitations as well as the multipurpose requirements of the hydro system. These constraints include:

(a) Physical limitations on reservoir storage volumes and discharge rates,

$$
\begin{aligned}
& V_{h j}^{\min } \leq V_{h j t} \leq V_{h j}^{\max }, \quad j \in \mathrm{N}_{h}, \quad t \in \mathrm{T} \\
& Q_{h j}^{\min } \leq Q_{h j t} \leq Q_{h j}^{\max }, \quad j \in \mathrm{N}_{h}, \quad t \in \mathrm{T}
\end{aligned}
$$

b) The continuity equation for the hydro reservoir network

$$
\begin{aligned}
V_{h j(t+1)} & =V_{h j t}+\mathrm{I}_{h j t}-Q_{h j t}-S_{h j t} \\
& +\sum_{l=1}^{R_{u j}}\left(Q_{h l\left(t-\tau_{l j}\right)}+S_{h l\left(t-\tau_{l j}\right)}\right), \quad j \in \mathrm{N}_{h}, \quad t \in \mathrm{T}
\end{aligned}
$$

(iv) Prohibited operating regions of water dischargerates

$$
Q_{h j} \in\left\{\begin{array}{l}
Q_{h j}{ }^{{ }^{\min }} \leq Q_{h j} \leq Q_{h j, 1}{ }^{L} \\
Q_{h j, k-1}{ }^{L} \leq Q_{h j} \leq Q_{h j, k}, k=2, \ldots n_{j} \\
Q_{h j, n_{j}}{ }^{u} \leq Q_{h j} \leq Q_{h j}{ }^{\max }
\end{array}\right.
$$

\section{Description of opposition-based differential evolution}

A brief description of differential evolution

Differential Evolution (DE) is a type of evolutionary algorithm originally proposed by Price and Storn [19] for optimization problems over a continuous domain. DE is exceptionally simple, significantly faster and robust. The basic idea of DE is to adapt the search during the evolutionary process. At the start of the evolution, the perturbations are large since parent populations are far away from each other. As the evolutionary process matures, the population converges to a small region and the perturbations adaptively become small. As a result, the evolutionary algorithm performs a global exploratory search during the early stages of the evolutionary process and local exploitation during the mature stage of the search. In DE the fittest of an offspring competes one-to-one with that of corresponding parent which is different from other evolutionary algorithms. This one-to-one competition gives rise to faster convergence rate. Price and Storn gave the working principle of DE with simple 
strategy in [19]. Later on, they suggested ten different strategies of DE [18]. Strategy-7 (DE/rad/1/bin) is the most successful and widely used strategy. The key parameters of control in $\mathrm{DE}$ are population size $\left(N_{P}\right)$, scaling factor $(F)$ and crossover rate $\left(C_{R}\right)$. The optimization process in $\mathrm{DE}$ is carried out with three basic operations: mutation, crossover and selection. The DE algorithm is described as follows:

\section{Initialization}

The initial population of $N_{P}$ vectors is randomly selected based on uniform probability distribution for all variables to cover the entire search uniformly. Each individual $X_{i}$ is a vector that contains as many parameters as the problem decision variables $D$. Random values are assigned to each decision parameter in every vector according to:

$$
\mathrm{X}_{i j}^{0} \sim U\left(\mathrm{X}_{j}^{\min }, \mathrm{X}_{j}^{\max }\right)
$$

where $i=1, \ldots ., N_{P}$ and $j=1, \ldots ., D ; X_{j}^{\min }$ and $X_{j}^{\max }$ are the lower and upper bounds of the $j$ th decision variable; $U$ $\left(\mathrm{X}_{j}^{\min }, \mathrm{X}_{j}^{\max }\right)$ denotes a uniform random variable ranging over $\left[\mathrm{X}_{j}^{\min }, \mathrm{X}_{j}^{\max }\right] . X_{i j}^{0}$ is the initial $j$ th variable of $i$ th population. All the vectors should satisfy the constraints. Evaluate the value of the cost function $f\left(\mathrm{X}_{i}^{0}\right)$ of each vector.

\section{Mutation}

DE generates new parameter vectors by adding the weighted difference vector between two population members to a third member. For each target vector $X_{i}^{k}$ at $k$ th iteration the noisy vector $X_{i^{/ k}}$ is obtained by

$$
\mathrm{X}_{i^{\prime k}}=\mathrm{X}_{a}^{k}+F\left(\mathrm{X}_{b}^{k}-\mathrm{X}_{c}^{k}\right), \quad i \in \mathrm{N}_{P}
$$

where $X_{a}^{k a}, X_{b}^{k}$ and $X_{c}^{k}$ are selected randomly from $N_{P}$ vectors at $k$ th iteration and $a \neq b \neq c \neq i$. The scaling factor $(F)$, in the range $0<F \leq 1.2$, controls the amount of perturbation added to the parent vector. The noisy vectors should satisfy the constraint.

\section{Crossover}

Perform crossover for each target vector $X_{i}^{k}$ with its noisy vector $X_{i^{/ k}}$ and create a trial vector $X_{i^{/ / k}}$ such that

$$
X_{i^{/ / k}}=\left\{\begin{array}{lll}
X_{i^{/ k}}, & \text { if } \quad \rho \leq C_{R} \\
X_{i}^{k}, & \text { otherwise }
\end{array} \quad, i \in N_{P}\right.
$$

where $\rho$ is an uniformly distributed random number within $[0,1]$. The crossover constant $\left(C_{R}\right)$, in the range $0 \leq C_{R} \leq 1$, controls the diversity of the population and aids the algorithm to escape from local optima.

\section{Selection}

Perform selection for each target vector, $X_{i}^{k}$ by comparing its cost with that of the trial vector, $X_{i / / k}$. The vector that has lesser cost of the two would survive for the next iteration.

$$
X_{i^{k+1}}=\left\{\begin{array}{ccc}
X_{i^{\prime / k}}, & \text { if } \quad f\left(X_{i^{/ / k}}\right) \leq f\left(X_{i}^{k}\right) \\
& & \\
X_{i}^{k}, & \text { otherwise } &
\end{array}\right.
$$

The process is repeated until the maximum number of iterations or no improvement is seen in the best individual after many iterations.

Figure 1 shows the flowchart of differential evolution.

\section{Opposition-based learning}

Opposition-based learning (OBL) was developed by Tizhoosh to improve candidate solution by considering

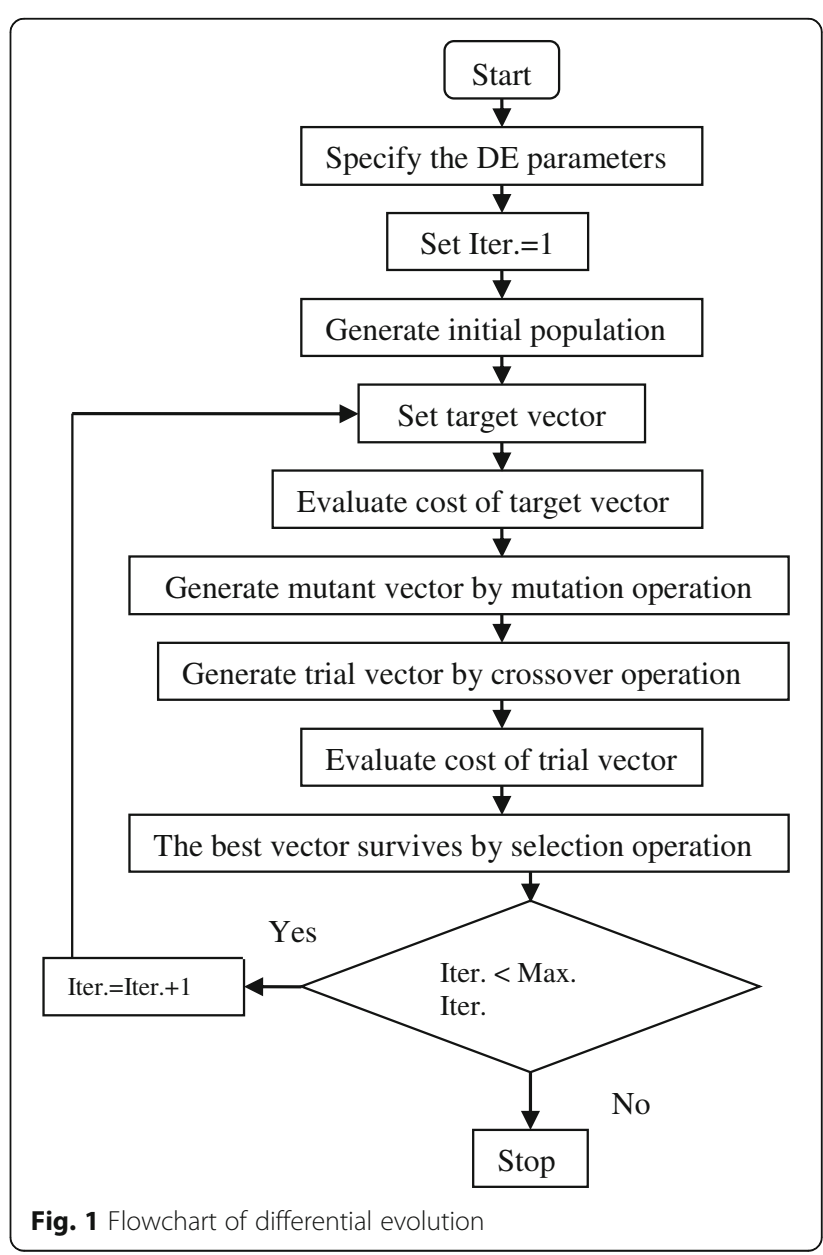


current population as well as its opposite population at the same time.

Evolutionary optimization methods start with some initial population and try to improve them toward some optimal solution. The process of searching terminates when some predefined criteria are satisfied. The process is started with random guesses in the absence of a priori information about the solution. The process can be improved by starting with a closer i.e. fitter solution by simultaneously checking the opposite solution. By doing this, the fitter one (guess or opposite guess) may be chosen as an initial solution. According to the theory of probability, $50 \%$ of the time, a guess is further from the solution than its opposite guess. Therefore, process starts with the closer of the two guesses. The same approach can be applied not only to the initial solution but also continuously to each solution in the current population.

\section{Definition of opposite number}

If $x$ be a real number between $[l b, u b]$, its opposite number is defined as

$$
\bar{x}=l b+l u-x
$$

Similarly, this definition can be extended to higher dimensions [21] as stated in the next sub-section.

\section{Definition of opposite point}

Let $X=\left(x_{1}, x_{2}, \ldots ., x_{n}\right)$ be a point in $n$ - dimensional space where $x_{i} \in\left[l b_{i}, u b_{i}\right]$ and $i \in 1,2, \ldots, n$. The opposite point $\bar{X}=\left(\overline{x_{1}}, \overline{x_{2}}, \ldots ., \overline{x_{n}}\right)$ is completely defined by its components as in (25).

$$
\overline{x_{i}}=l b_{i}+u b_{i}-x_{i}
$$

By employing the definition of opposite point, the opposition-based optimization is defined in the following sub-section.

\section{Opposition-based optimization}

Let $X=\left(x_{1}, x_{2}, \ldots, x_{n}\right)$ be a point in $n$ - dimensional space i.e. a candidate solution. Assume $f=(\bullet)$ is a fitness function which is used to measure the candidate's fitness. According to the definition of the opposite point, $\bar{X}=\left(\overline{x_{1}}, \overline{x_{2}}, \ldots . ., \overline{x_{n}}\right)$ is the opposite of $X=\left(x_{1}, x_{2}, \ldots, x_{n}\right)$. Now, if $f(\bar{X})<f(X)$ (for a minimization problem), then point $X$ can be replaced with $\bar{X}$; otherwise, the process is continued with $X$. Hence, the point and its opposite point are evaluated simultaneously in order to continue with the fitter one.

\section{Opposition-based differential evolution}

In the present work, the concept of the oppositionbased learning [21] is incorporated in differential evolution. The original DE is chosen as a parent algorithm and the opposition-based ideas are embedded in $\mathrm{DE}$.

Figure 2 shows the flowchart of ODE algorithm.

\section{Simulation results}

Two test problems, two fixed head hydrothermal systems and three hydrothermal multi-reservoir cascaded hydroelectric test systems having prohibited operating zones and thermal units with valve point loading are investigated. The computational results have been used to compare the performance of the proposed ODE method with that of other evolutionary methods. The proposed ODE algorithm and DE algorithm used in this paper are implemented by using MATLAB 7.0 on a PC (PentiumIV, $80 \mathrm{~GB}, 3.0 \mathrm{GHz}$ ).

\section{Simple examples}

Example 1: Consider the maximization problem [31]

$$
\begin{aligned}
\max _{x_{1}, x_{2}} f\left(x_{1}, x_{2}\right)= & 21.5+x_{1} \sin \left(4 \pi x_{1}\right) \\
& +x_{2} \sin \left(20 \pi x_{2}\right)
\end{aligned}
$$

where $-3.0 \leq x_{1} \leq 12.1$ and $4.1 \leq x_{2} \leq 5.8$

This function is multimodal. The problem is solved by using ODE.

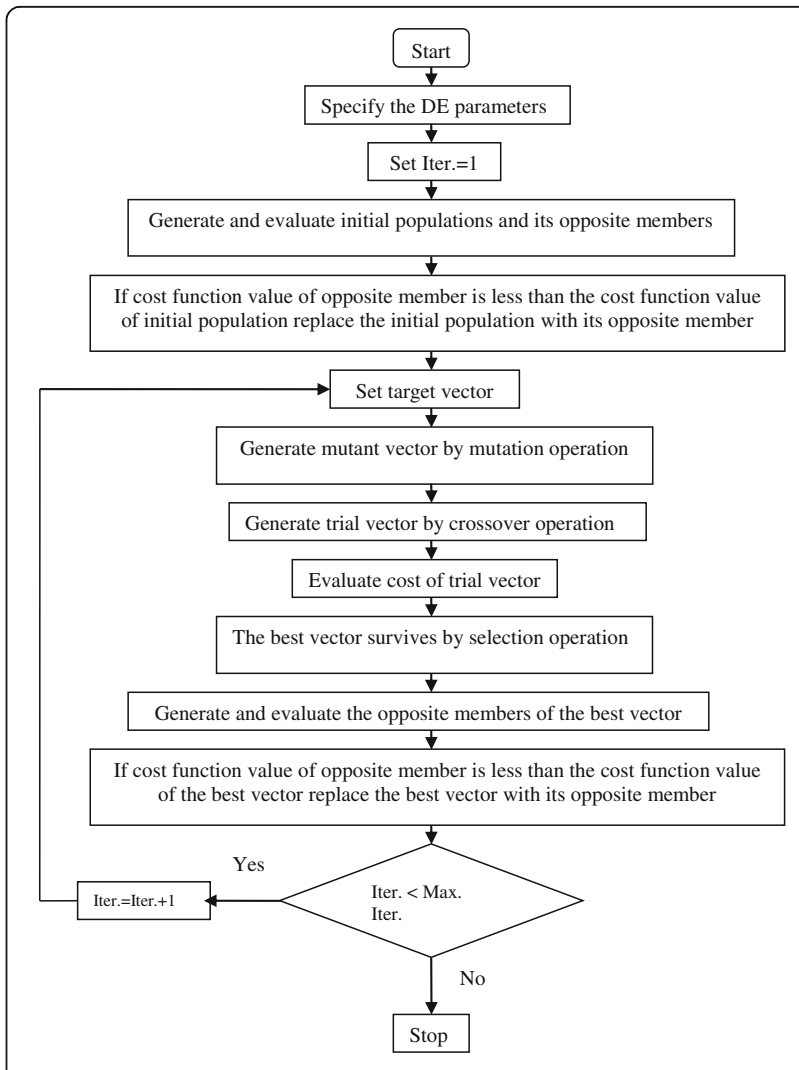

Fig. 2 Flowchart of ODE 
Table 1 Best optimum value, the variables corresponding to the best optimum value, average value, worst value and average CPU time for example 1

\begin{tabular}{|c|c|c|c|c|c|}
\hline Method & $x^{*}$ & $f\left(x^{*}\right)$ & $\begin{array}{l}\text { Average } \\
\text { value }\end{array}$ & $\begin{array}{l}\text { Worst } \\
\text { value }\end{array}$ & $\begin{array}{l}\text { CPU } \\
\text { time (sec) }\end{array}$ \\
\hline$\overline{\mathrm{ODE}}$ & $\begin{array}{l}\text { [12.1000, } \\
5.7227]\end{array}$ & 38.9377 & 38.9377 & 38.9377 & 0.0473 \\
\hline $\mathrm{DE}$ & $\begin{array}{l}{[12.1000} \\
5.7228]\end{array}$ & 38.9375 & 38.9373 & 38.9371 & 0.0469 \\
\hline
\end{tabular}

Here, the population size $\left(N_{P}\right)$, scaling factor $(F)$, crossover constant $\left(C_{R}\right)$ and maximum iteration number have been selected 10, 0.3, 1.0 and 50 respectively. The best optimum value, the variables corresponding to the best optimum value, average and worst value and average CPU time among 100 runs of solutions obtained from proposed ODE and DE for example 1 have been shown in Table 1. Figure 3 shows the nature of convergence obtained from ODE and DE for example 1.

\section{Example 2: Consider the minimization problem [31]}

$$
\min _{x_{1}, x_{2}} f\left(x_{1}, x_{2}\right)=\sum_{i=1}^{5} i \cos \left[(i+1) x_{1}+i\right] \sum_{i=1}^{5} i \cos \left[(i+1) x_{2}+i\right]
$$

where $-10 \leq x_{1} \leq 10$ and $-10 \leq x_{2} \leq 10$

This function has 760 local minima, 18 of which are global minima with -186.73 . The problem is solved by using ODE. Here, the population size $\left(N_{P}\right)$, scaling factor $(F)$, crossover constant $\left(C_{R}\right)$ and maximum iteration number have been selected 10, 0.3, 1 and 100 respectively for the example under consideration.

To validate the proposed ODE based approach, the same example is solved by using DE.

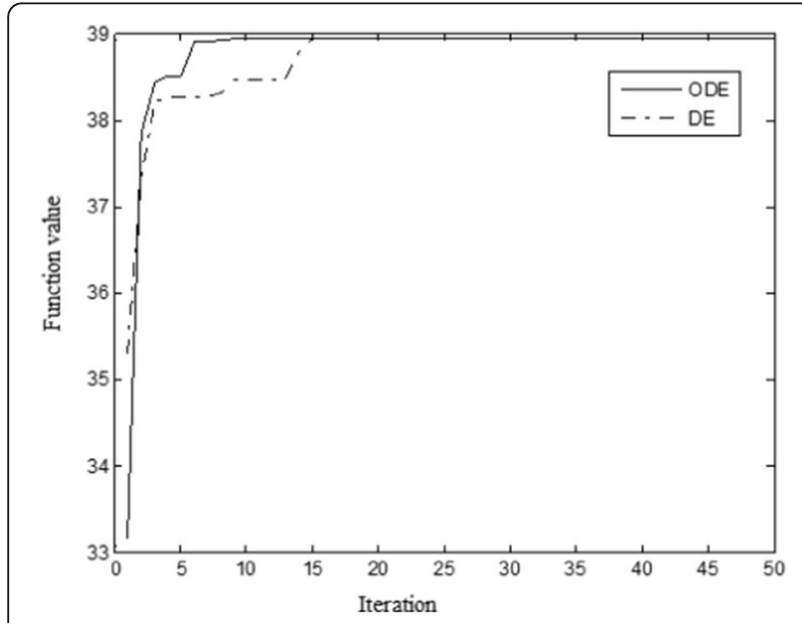

Fig. 3 Convergence characteristic of example 1
Table 2 Best optimum value, the variables corresponding to the best optimum value, average value, worst value and average CPU time for example 2

\begin{tabular}{lllllc}
\hline Method & $x^{*}$ & $f\left(x^{*}\right)$ & $\begin{array}{l}\text { Average } \\
\text { value }\end{array}$ & Worst value & $\begin{array}{l}\text { CPU } \\
\text { time (sec) }\end{array}$ \\
\hline ODE & {$[5.4830$,} & -186.7309 & -186.7309 & -186.7309 & 0.0625 \\
& $4.8581]$ & & & & \\
DE & {$[-7.7084$,} & -186.7308 & -186.7307 & -186.7303 & 0.0781 \\
& $-7.0834]$ & & & & \\
\hline
\end{tabular}

In case of $\mathrm{DE}$, the population size $\left(N_{P}\right)$, scaling factor $(F)$, crossover constant $\left(C_{R}\right)$ and maximum iteration number have been selected as 10, 0.3, 1.0 and 100 respectively. Table 2 summarizes the best optimum value, the variables corresponding to the best optimum value, average and worst value and average CPU time among 100 runs of solutions obtained from proposed ODE and $\mathrm{DE}$ for example 2. Figure 4 depicts the nature of convergence obtained from ODE and DE for example 2.

Figure 4 depicts the nature of convergence obtained from ODE and DE for example 2.

\section{Case study of fixed head hydrothermal system Test system 1}

This system consists of two hydro plants and two thermal plants whose characteristics and load demands are given in Tables 13, 14 and 15 respectively in Appendix 1. Transmission loss formula coefficients are also given in the Appendix 1. Hydro plant data is taken from [32].

The problem is solved by using both the proposed ODE and DE. Here, the population size $\left(N_{P}\right)$, scaling factor $(F)$, crossover rate $\left(C_{R}\right)$ and the maximum iteration number $\left(N_{\max }\right)$ have been selected as 100, 1.0, 1.0 and 100 respectively for the test system under consideration.

The optimal hydrothermal generation obtained by the proposed ODE and DE are provided in Tables 3 and 4 respectively. The best, average and worst cost and

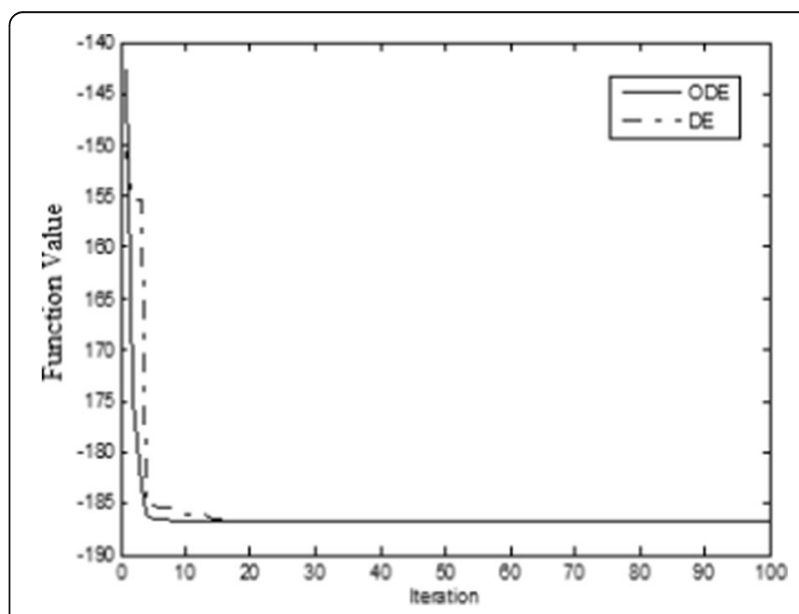

Fig. 4 Convergence characteristic of example 2 
Table 3 Results obtained from ODE of test system 1 of fixed head hydrothermal system

\begin{tabular}{lllll}
\hline Sub-interval & $P_{h 1}(\mathrm{MW})$ & $P_{h 2}(\mathrm{MW})$ & $P_{s 1}(\mathrm{MW})$ & $P_{s 2}(\mathrm{MW})$ \\
\hline 1 & 244.5860 & 90.7689 & 179.4953 & 424.9773 \\
2 & 307.3581 & 163.3383 & 228.7850 & 570.1572 \\
3 & 285.4852 & 139.2931 & 211.2739 & 522.5895 \\
\hline
\end{tabular}

Table 4 Results obtained from DE for test system 1 of fixed head hydrothermal system

\begin{tabular}{lllll}
\hline Sub-interval & $P_{h 1}(\mathrm{MW})$ & $P_{h 2}(\mathrm{MW})$ & $P_{s 1}(\mathrm{MW})$ & $P_{\text {s2 }}(\mathrm{MW})$ \\
\hline 1 & 240.3807 & 85.6583 & 206.3934 & 407.6673 \\
2 & 310.1176 & 167.5754 & 206.3934 & 585.2895 \\
3 & 286.6845 & 139.7912 & 206.3934 & 525.7479 \\
\hline
\end{tabular}

Table 5 Comparison of performance for Test System 1 of fixed head hydrothermal system

\begin{tabular}{lllll}
\hline Techniques & $\begin{array}{l}\text { Best } \\
\text { cost }(\$)\end{array}$ & $\begin{array}{l}\text { Average } \\
\text { cost }(\$)\end{array}$ & Worst cost $(\$)$ & CPU time (s) \\
\hline ODE & 66030.85 & 66031.68 & 66032.46 & 40.31 \\
DE & 66060.74 & 66061.44 & 66064.14 & 36.01 \\
AIS [12] & 66117 & - & - & 53.43 \\
PSO [12] & 66166 & - & - & 71.62 \\
EP [12] & 66198 & - & - & 75.48 \\
\hline
\end{tabular}

average CPU time among 100 runs of solutions obtained from proposed ODE and DE method are summarized in Table 5. The cost obtained from artificial immune system (AIS) [14], particle swarm optimization (PSO) [14] and evolutionary programming (EP) [14] are also shown in Table 5. The cost convergence characteristic obtained from proposed ODE and DE is shown in Fig. 5. It is seen

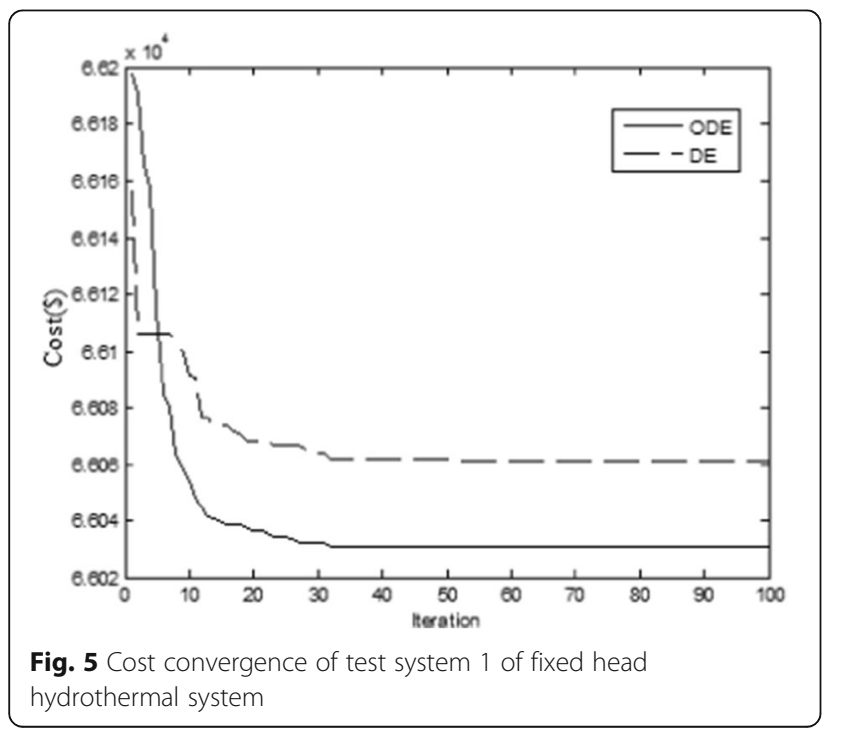

from Table 5 that the cost found by using ODE is the lowest among all other methods.

\section{Test system 2}

This system comprises of two hydro plants and four thermal plants whose characteristics and load demands are given in Tables 16, 17 and 18 respectively in Appendix 2. Transmission loss formula coefficients are also given in the Appendix 2.

The problem is solved by using both the proposed ODE and DE. Here, the population size $\left(N_{P}\right)$, scaling factor $(F)$, crossover rate $\left(C_{R}\right)$ and the maximum iteration number $\left(N_{\max }\right)$ have been selected as $100,1.0,1.0$ and 200 respectively for the test system under consideration. The optimal hydrothermal generation obtained by the proposed ODE and DE are provided in Tables 6 and 7 respectively. The best, average and worst cost and average CPU time among 100 runs of solutions obtained from proposed ODE and DE are summarized in Table 8. The cost obtained from artificial immune system (AIS)

Table 6 Results obtained from ODE of test system 2 of fixed head hydrothermal system

\begin{tabular}{lllllll}
\hline $\begin{array}{l}\text { Sub- } \\
\text { interval }\end{array}$ & $P_{h 1}(\mathrm{MW})$ & $P_{h 2}(\mathrm{MW})$ & $P_{s 1}(\mathrm{MW})$ & $P_{s 2}(\mathrm{MW})$ & $P_{s 3}(\mathrm{MW})$ & $P_{s 4}(\mathrm{MW})$ \\
\hline 1 & 172.6478 & 317.8272 & 93.6207 & 174.7438 & 109.2596 & 50.3779 \\
2 & 243.8370 & 411.3216 & 124.8716 & 174.6929 & 123.6025 & 50.1150 \\
3 & 209.7780 & 351.8750 & 116.1764 & 174.7282 & 120.3243 & 50.0519 \\
4 & 249.8641 & 499.8741 & 124.8642 & 174.9127 & 222.4536 & 68.0992 \\
\hline
\end{tabular}

Table 7 Results obtained from DE of test system 2 of fixed head hydrothermal system

\begin{tabular}{lllllll}
\hline $\begin{array}{l}\text { Sub- } \\
\text { interval }\end{array}$ & $P_{h 1}(\mathrm{MW})$ & $P_{h 2}(\mathrm{MW})$ & $P_{s 1}(\mathrm{MW})$ & $P_{s 2}(\mathrm{MW})$ & $P_{s 3}(\mathrm{MW})$ & $P_{s 4}(\mathrm{MW})$ \\
\hline 1 & 184.4627 & 303.6346 & 88.3611 & 174.7233 & 116.2664 & 50.9170 \\
2 & 241.0344 & 419.5791 & 117.4402 & 174.8712 & 124.7407 & 50.9397 \\
3 & 201.9931 & 357.2371 & 123.3403 & 173.9739 & 115.3547 & 51.0280 \\
4 & 249.3076 & 499.1428 & 124.0676 & 174.7184 & 221.4260 & 71.3501 \\
\hline
\end{tabular}

Table 8 Comparison of performance for Test System 2 of fixed head hydrothermal system

\begin{tabular}{llllc}
\hline Techniques & $\begin{array}{l}\text { Best } \\
\text { cost }(\$)\end{array}$ & $\begin{array}{l}\text { Average } \\
\text { cost }(\$)\end{array}$ & $\begin{array}{l}\text { Worst } \\
\text { cost }(\$)\end{array}$ & $\begin{array}{l}\text { CPU } \\
\text { time (s) }\end{array}$ \\
\hline ODE & 92817.01 & 92819.81 & 92822.68 & 46.09 \\
DE & 93107.34 & 93110.45 & 93114.07 & 41.53 \\
AIS [12] & 93950 & - & - & 59.14 \\
PSO [12] & 94126 & - & - & 83.54 \\
EP [12] & 94250 & - & - & 67.82 \\
\hline
\end{tabular}




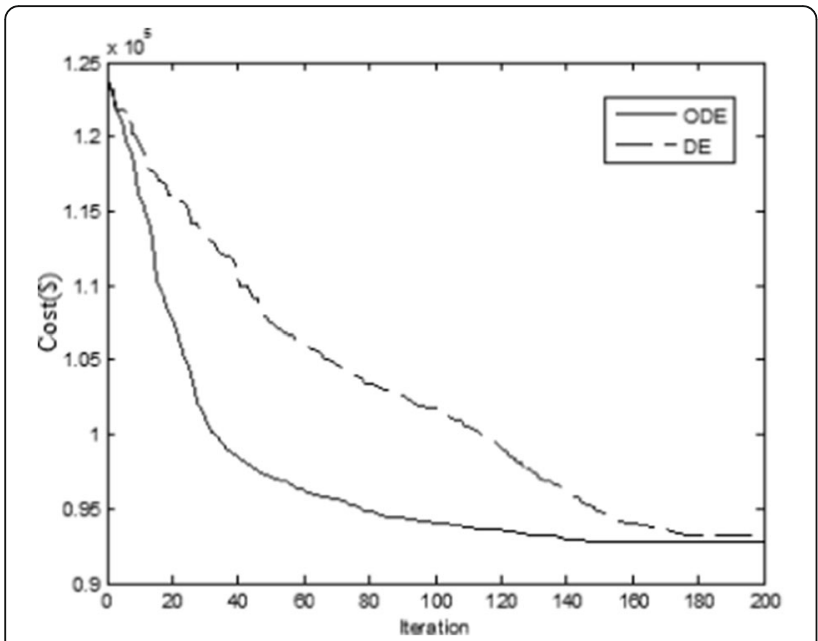

Fig. 6 Cost convergence of test system 2 of fixed head hydrothermal system

[14], particle swarm optimization (PSO) [14] and evolutionary programming (EP) [14] are also shown in Table 8. The cost convergence characteristic obtained from proposed ODE and DE is depicted in Fig. 6. It is seen from Table 8 that the cost found by using ODE is the lowest among all other methods.

\section{Case study of variable head hydrothermal system}

Three variable head hydrothermal test systems are considered to inspect and verify the proposed ODE method.

\section{Test system 1}

This test system considers a multi-chain cascade of four reservoir hydro plants and an equivalent thermal plant. The entire scheduling period is 1 day and divided into 24 intervals. Here, two cases are considered.

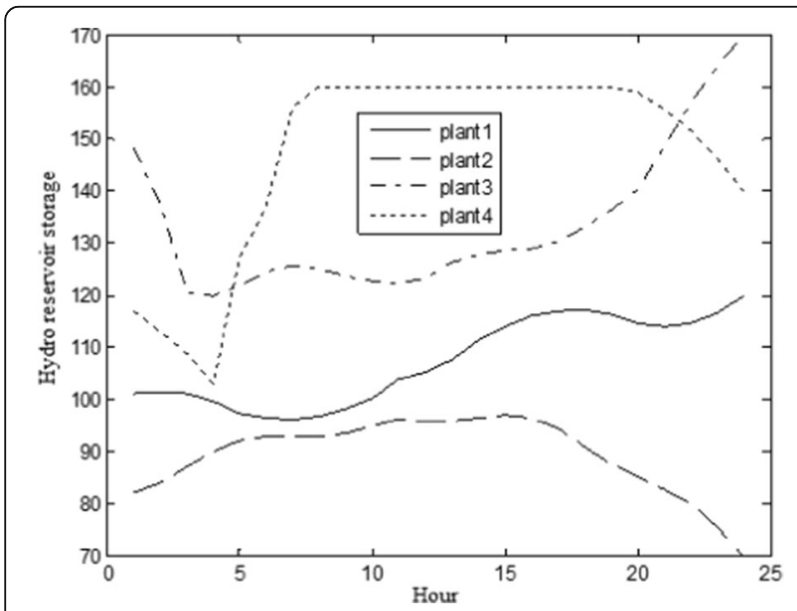

Fig. 7 Hydro reservoir storage volumes for case of test system 1 of variable head hydrothermal system
Table 9 Comparison of performance for case 1 of Test System 1 of variable head hydrothermal system

\begin{tabular}{lllll}
\hline Techniques & Best cost (\$) & $\begin{array}{l}\text { Average } \\
\text { cost }(\$)\end{array}$ & Worst cost (\$) & $\begin{array}{l}\text { CPU } \\
\text { time (s) }\end{array}$ \\
\hline ODE & 917199.44 & 917208.56 & 917221.37 & 257.03 \\
DE & 918480.03 & 918494.37 & 918504.47 & 256.75 \\
TLBO [16] & 922373.39 & 922462.24 & 922873.81 & - \\
IPSO [13] & 922553.49 & - & - & - \\
MDE [10] & 922556.44 & - & - & - \\
IFEP [9] & 930129.82 & 930290.13 & 930881.92 & 1033.20 \\
GA [7] & 926707.00 & - & - & - \\
\hline
\end{tabular}

Case 1: Here fuel cost is considered as a quadratic function of the power from the composite thermal plant. The detailed parameters for this case come from [7].

The problem is solved by using both the proposed ODE and DE. Here, the population size $\left(N_{P}\right)$, scaling factor $(F)$, crossover constant $\left(C_{R}\right)$ and maximum iteration number have been selected 100, 1, 1 and 300 respectively for this case.

The optimal hourly discharges and hydrothermal generation obtained by the proposed ODE method are provided in Tables 19 and 20 in Appendix 3 respectively. Figure 7 depicts the reservoir storage volumes of four hydro plants obtained from ODE. The best, average and worst cost and average CPU time among 100 runs of solutions obtained from proposed ODE and DE are summarized in Table 9. The cost obtained from modified differential evolution (MDE) [10], improved particle swarm optimization (IPSO) [13], teaching learning based optimization (TLBO) [16], improved fast evolutionary programming (IFEP) [9] and genetic algorithm (GA) [7] methods are also shown in Table 9. The cost convergence characteristic obtained from proposed ODE and DE is shown in Fig. 8. It is seen

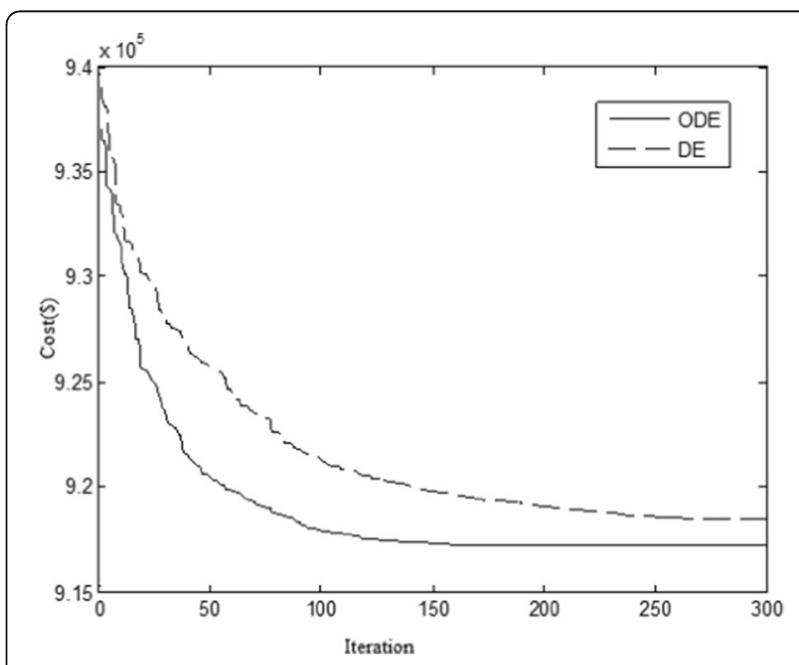

Fig. 8 Cost convergence characteristics for case 1 of the system 1 of variable head hydrothermal system 


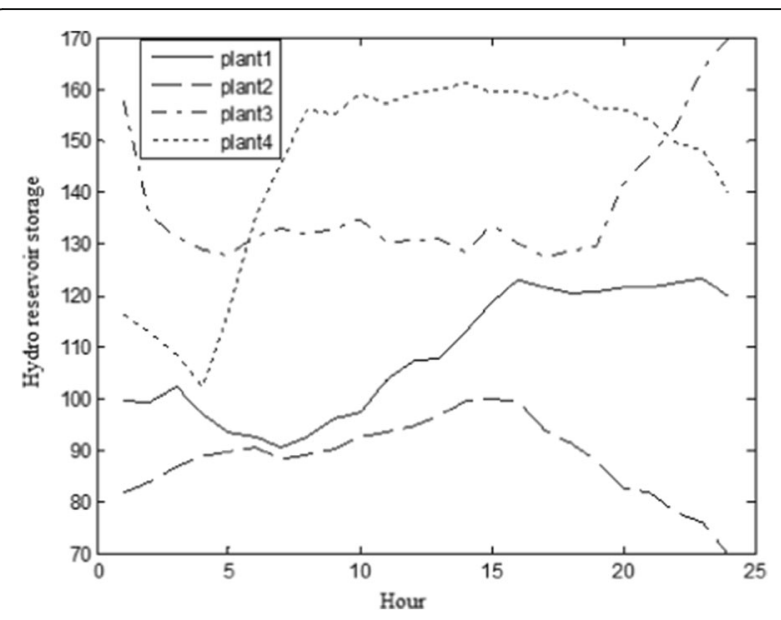

Fig. 9 Hydro reservoir storage volumes for case 2 of test system 1 of variable head hydrothermal system

from Table 9 that the cost found by using ODE is the lowest among all other methods.

Case 2: Here prohibited operating zones of hydro plants and valve point loading of thermal generator are considered. The detailed parameters for this case come from [9].

The problem is solved by using both the proposed ODE and DE. Here, the population size $\left(N_{P}\right)$, scaling factor $(F)$, crossover constant $\left(C_{R}\right)$ and maximum iteration number have been selected 100, 1,1 and 400 respectively for this case.

The optimal hourly discharges and hydrothermal generation obtained by the proposed ODE method are provided in Tables 21 and 22 respectively in Appendix 3. Figure 9 shows the reservoir storage volumes of four hydro plants obtained from ODE. The best, average and worst cost and average CPU time among 100 runs of solutions obtained from proposed ODE and DE are summarized in Table 10. The cost obtained from improved fast evolutionary programming (IFEP) [9], improved particle swarm optimization (IPSO) [13] and teaching learning based optimization (TLBO) [16] method is also shown in Table 10. The cost convergence characteristic obtained from proposed ODE and DE is shown in Fig. 10. It is seen from Table 10 that the cost found by using ODE is the lowest among all other methods.

Table 10 Comparison of performance for case 2 of test system 1 of variable head hydrothermal system

\begin{tabular}{llllll}
\hline Techniques & ODE & DE & IFEP [9] & TLBO [16] & IPSO [13] \\
\hline Best cost (\$) & 923230.63 & 924069.73 & 933949.25 & 924550.78 & 925978.84 \\
Average cost (\$) & 923242.45 & 924083.56 & 938508.87 & 924702.43 & - \\
Worst cost (\$) & 923255.37 & 924096.28 & 942593.02 & 925149.06 & - \\
CPU time (s) & 264.73 & 258.65 & 1450.90 & - & - \\
\hline
\end{tabular}

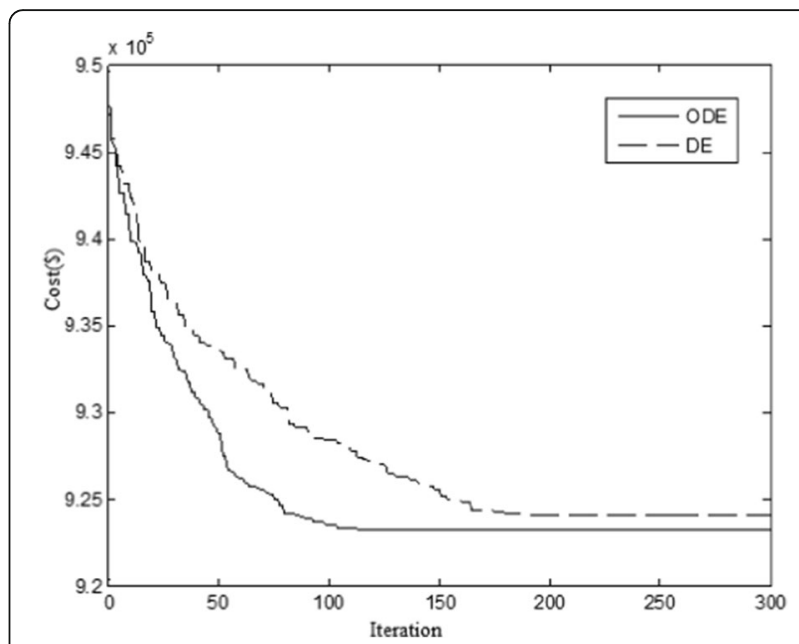

Fig. 10 Cost convergence characteristics for case 2 of the system 1 of variable head hydrothermal system

\section{Test system 2}

This system considers a multi-chain cascade of four reservoir hydro plants and three thermal plants. The entire scheduling period is 1 day and divided into 24 intervals. The effect of valve point loading is considered. Transmission loss is also considered. The detailed parameters for this case are taken from [10].

The problem is solved by using both the proposed ODE and DE. Here, the population size $\left(N_{P}\right)$, scaling factor $(F)$, crossover constant $\left(C_{R}\right)$ and maximum iteration number have been selected 100, 1, 1 and 300 respectively for this case.

The optimal hourly discharges and hydrothermal generation obtained by the proposed ODE method are provided in Tables 23 and 24 respectively in Appendix 3. Figure 11 shows the reservoir storage volumes of four hydro plants obtained from ODE.

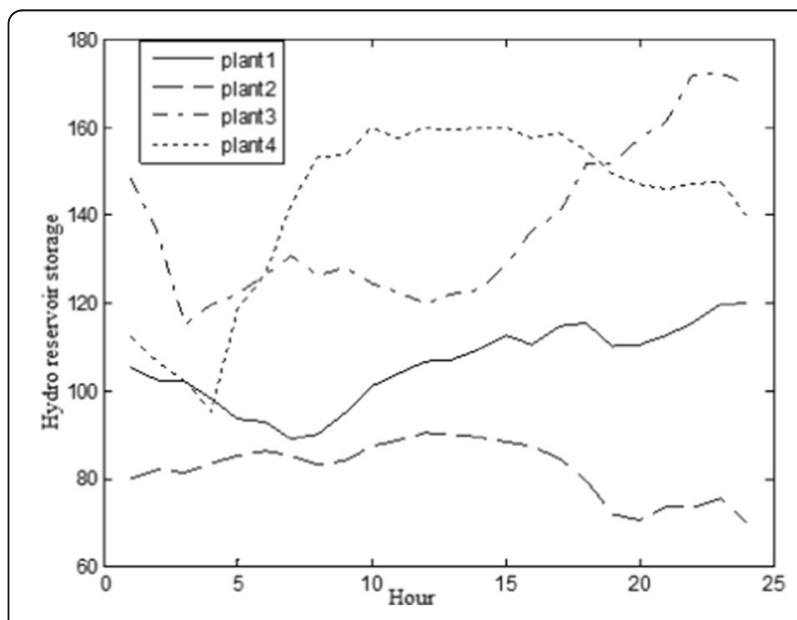

Fig. 11 Hydro reservoir storage volumes of test system 2 of variable head hydrothermal system 
Table 11 Comparison of performance of test system 2 of variable head hydrothermal system

\begin{tabular}{llllll}
\hline Techniques & ODE & DE & MDE [10] & TLBO [3] & CSA [15] \\
\hline Best cost (\$) & 42322.23 & 43068.01 & 43435.41 & 42385.88 & 42440.574 \\
Average cost (\$) & 42330.53 & 43079.52 & - & 42407.23 & - \\
Worst cost (\$) & 42339.36 & 43083.05 & - & 42441.36 & - \\
CPU time (s) & 304.05 & 298.72 & - & - & - \\
\hline
\end{tabular}

The best, average and worst cost and average CPU time among 100 runs of solutions obtained from proposed ODE and DE are shown in Table 11. The cost obtained from modified differential evolution (MDE) [10], clonal selection algorithm (CSA) [15] and teaching learning based optimization (TLBO) [16] is also shown

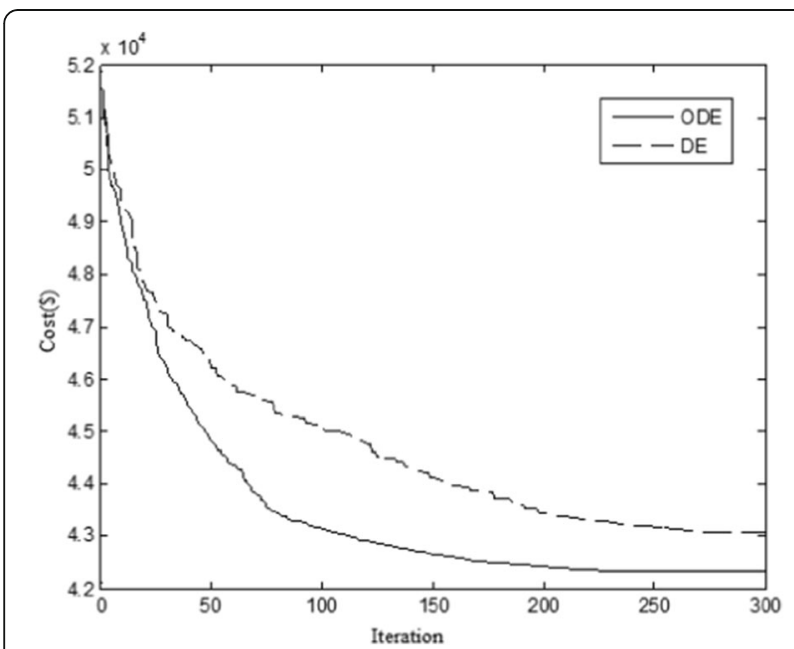

Fig. 12 Cost convergence characteristics of test system 2 of variable head hydrothermal system

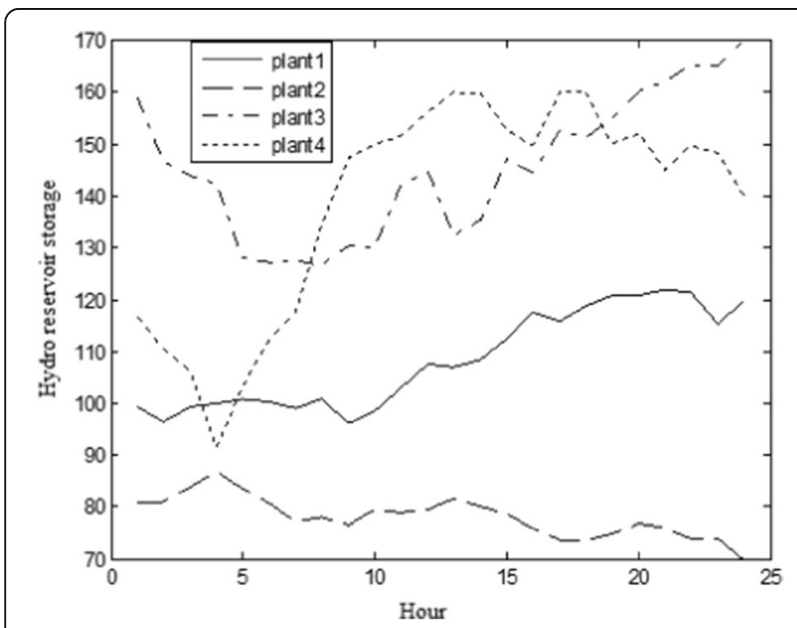

Fig. 13 Hydro reservoir storage volumes of test system 3 of variable head hydrothermal system
Table 12 Comparison of performance for test system 3 of variable head hydrothermal system

\begin{tabular}{llll}
\hline Techniques & ODE & DE & DE [12] \\
\hline Best cost (\$) & 170452.35 & 170915.57 & 170964.15 \\
Average cost (\$) & 170459.78 & 170924.41 & - \\
Worst cost (\$) & 170468.52 & 170935.28 & - \\
CPU time (s) & 472.51 & 459.92 & - \\
\hline
\end{tabular}

in Table 11. The cost convergence characteristic obtained from proposed ODE and DE is shown in Fig. 12. It is seen from Table 11 that the cost found by using ODE is the lowest among all other methods.

\section{Test system 3}

This system considers a multi-chain cascade of four reservoir hydro plants and ten thermal plants. The entire scheduling period is 1 day and divided into 24 intervals. The effect of valve point loading is taken into account. Here transmission loss is not considered. The detailed data for this system is taken from [12].

The problem is solved by using both the proposed ODE and DE. Here, the population size $\left(N_{P}\right)$, scaling factor $(F)$, crossover constant $\left(C_{R}\right)$ and maximum iteration number have been selected 100, 1, 1 and 900 respectively for this case.

The optimal hourly discharges and hydrothermal generation obtained by the proposed ODE method are provided in Tables 25 and 26 respectively in Appendix 3. Figure 13 shows the reservoir storage volumes of four hydro plants obtained from ODE. The best, average and worst cost and average CPU time among 100 runs of solutions obtained from proposed

ODE and DE are summarized in Table 12. The cost obtained from differential evolution (DE) [12] method is

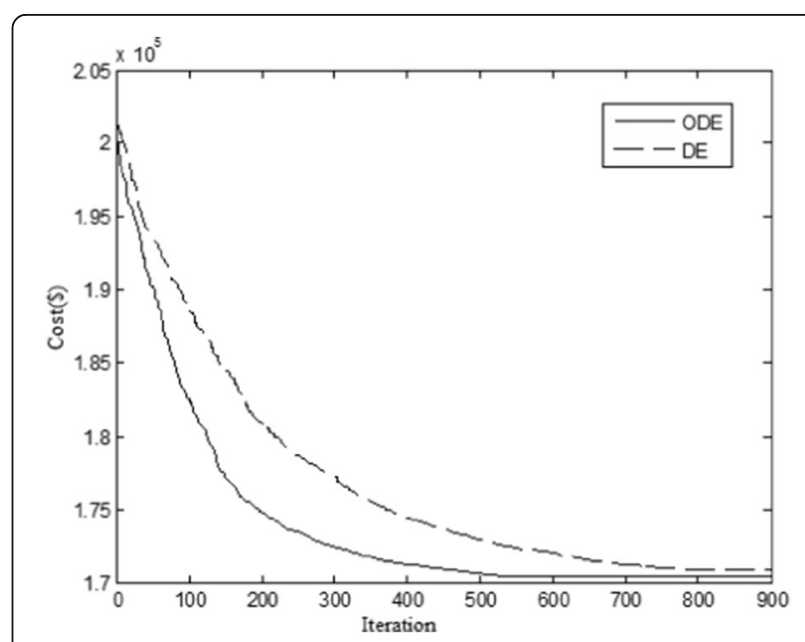

Fig. 14 Cost convergence characteristics for test system 3 of variable head hydrothermal system 
also shown in Table 12. The cost convergence characteristic obtained from proposed ODE and DE is shown in Fig. 14. It is seen from Table 12 that the cost found by using ODE is the lowest among all other methods.

It is observed from in Tables 20, 22, 24 and 26 respectively in Appendix 3 that the third hydro unit has no output during some time interval. This is because of the fact that output from a particular hydro unit during a specified time interval depends on the availability of water, reservoir storage volume limit, water transport delay between cascaded reservoirs and on the system configuration as a whole. Depending on the system configuration and constraints for the present problem, this has happened in case of the third hydro unit.

\section{Conclusion}

In this paper, opposition-based differential evolution is demonstrated and presented to solve the hydrothermal scheduling problem. The proposed oppositionbased differential evolution method has been successfully applied to two test problems, two fixed head hydrothermal test systems and three hydrothermal multi-reservoir cascaded hydroelectric test systems having prohibited operating zones and thermal units with valve point loading. The results have been compared with those obtained by other evolutionary algorithms reported in the literature. It is seen from the comparisons that the proposed opposition-based differential evolution method performs better than other evolutionary algorithms in the literature.

\section{Nomenclature}

$a_{s i}, b_{s i}, c_{s i}, d_{s i}, e_{s i}$ : cost curve coefficients of $i$ th thermal unit

$P_{\text {sim }}$ : power output of $i$ th thermal generator during subinterval $m$

$P_{s i}^{\min }, P_{s i}^{\max }:$ lower and upper generation limits for $i$ th thermal unit

$t_{m}$ : duration of subinterval $m$.

$P_{\text {hjm }}$ : power output of $j$ th hydro unit during subinterval $m$

$P_{D m}$ : load demand during subinterval $m$

$P_{L m}$ : transmission loss during subinterval $m$

$B_{l r}$ : loss formula coefficients.

$a_{0 h j}, a_{1 h j}$, and $a_{2 h j}$ : coefficients for water discharge rate function of $j$ th hydro generator

$W_{h j}$ : prespecified volume of water available for generation by $j$ th hydro unit during the scheduling period.

$P_{h j}^{\min }, P_{h j}^{\max }$ : lower and upper generation limits for $j$ th hydro unit

$P_{\text {sit }}$ : output power of $i$ th thermal unit at time $t$

$P_{D t}$ : load demand at time $t$

$P_{L t}$ : transmission loss at time $t$
$P_{h j t}$ : output power of $j$ th hydro unit at time $t$

$C_{1 j}, C_{2 j}, C_{3 j}, C_{4 j}, C_{5 j}, C_{6 j}$ : power generation coefficients of $j$ th hydro unit

$Q_{h j t}$ : water discharge rate of $j$ th reservoir at time $t$

$V_{\text {hjt }}$ : storage volume of $j$ th reservoir at time $t$

$Q_{h j}^{\min }, Q_{h j}^{\max }$ : minimum and maximum water discharge rate of $j$ th reservoir

$Q_{h j, k}^{L}, Q_{h j, k}^{U}$ : lower and upper bounds of $k$ th prohibited zones of hydro unit $j$

$V_{h j}^{\min }, V_{h j}^{\max }$ : minimum and maximum storage volume of $j$ th reservoir

$I_{\text {hjt }}$ : inflow rate of $j$ th reservoir at time $t$

$R_{u j}$ : number of upstream units directly above $j$ th hydro plant

$S_{h j t}$ : spillage of $j$ th reservoir at time $t$

$\tau_{l j}$ : water transport delay from reservoir $l$ to $j$

$t, T$ : time index and scheduling period

$N_{s}$ : number of thermal generating units

$N_{h}$ : number of hydro generating units

$n_{j}$ : number of prohibited zones for hydro unit $j$

$k$ : index of prohibited zones of a hydro unit

\section{Appendix 1}

Table 13 Hydro system data of test system 1

\begin{tabular}{lllllll}
\hline Unit & $a_{0 h}$ & $a_{1 h}$ & $a_{2 h}$ & $W_{h}$ & $P_{h}^{\min }$ & $P_{h}^{\max }$ \\
& MCF/h & MCF/MWh & MCF/(MW)2 h & MCF & MW & MW \\
\hline 1 & 1.980 & 0.306 & 0.000216 & 2500 & 0 & 400 \\
2 & 0.936 & 0.612 & 0.000360 & 2100 & 0 & 300 \\
\hline
\end{tabular}

Table 14 Thermal generator data of test system 1

\begin{tabular}{llllllll}
\hline Unit & $P_{s}^{\min }$ & $P_{s}^{\max }$ & $a_{s}$ & $b_{s}$ & $c_{s}$ & $d_{s}$ & $e_{s}$ \\
& $\mathrm{MW}$ & $\mathrm{MW}$ & $\$ / \mathrm{h}$ & $\$ / \mathrm{MWh}$ & $\$ /(\mathrm{MW}) 2 \mathrm{~h}$ & $\$ / \mathrm{h}$ & $1 / \mathrm{MW}$ \\
\hline 1 & 50 & 300 & 25 & 3.2 & 0.0025 & 0 & 0 \\
2 & 50 & 700 & 30 & 3.4 & 0.0008 & 0 & 0 \\
\hline
\end{tabular}

Table 15 Load demands of test system 1

\begin{tabular}{lll}
\hline Sub-interval & Duration (hr) & PD (MW) \\
\hline 1 & 8 & 900 \\
2 & 8 & 1200 \\
3 & 8 & 1100 \\
\hline
\end{tabular}

The transmission loss formula coefficients of test system 1 are

$$
\mathrm{B}=\left[\begin{array}{llll}
0.000015 & 0.000140 & 0.000010 & 0.000015 \\
0.000010 & 0.000060 & 0.000010 & 0.000013 \\
0.000015 & 0.000010 & 0.000068 & 0.000065 \\
0.000015 & 0.000013 & 0.000065 & 0.000070
\end{array}\right]
$$




\section{Appendix 2}

Table 16 Hydro system data of test system 2

\begin{tabular}{lllllll}
\hline Unit & $a_{0 h}$ & $a_{1 h}$ & $a_{2 h}$ & $W_{h}$ & $P_{h}^{\min }$ & $P_{h}^{\max }$ \\
& acre-ft/h & acre-ft/MWh & acre-ft/(MW)2 h & acre-ft & MW & MW \\
\hline 1 & 260 & 8.5 & 0.00986 & 125000 & 0 & 250 \\
2 & 250 & 9.8 & 0.01140 & 286000 & 0 & 500 \\
\hline
\end{tabular}

Table 17 Thermal generator data of test system 2

\begin{tabular}{llllllll}
\hline Unit & $P_{s}^{\min }$ & $P_{s}^{\max }$ & $a_{s}$ & $b_{s}$ & $c_{s}$ & $d_{s}$ & $e_{s}$ \\
& $\mathrm{MW}$ & $\mathrm{MW}$ & $\$ / \mathrm{h}$ & $\$ / \mathrm{MWh}$ & $\$ /(\mathrm{MW}) 2 \mathrm{~h}$ & $\$ / \mathrm{h}$ & $\mathrm{rad} / \mathrm{MW}$ \\
\hline 3 & 20 & 125 & 10 & 3.25 & 0.0083 & 12 & 0.0450 \\
4 & 30 & 175 & 10 & 2.00 & 0.0037 & 18 & 0.0370 \\
5 & 40 & 250 & 20 & 1.75 & 0.0175 & 16 & 0.0380 \\
6 & 50 & 300 & 20 & 1.00 & 0.0625 & 14 & 0.0400 \\
\hline
\end{tabular}

Table 18 Load demands of test system 2

\begin{tabular}{lll}
\hline Sub-interval & Duration (hr) & PD (MW) \\
\hline 1 & 12 & 900 \\
2 & 12 & 1100 \\
3 & 12 & 1000 \\
4 & 12 & 1200 \\
\hline
\end{tabular}

The transmission loss formula coefficients are of test system 2

$\mathrm{B}=\left[\begin{array}{llllll}0.000049 & 0.000014 & 0.000015 & 0.000015 & 0.000020 & 0.000017 \\ 0.000014 & 0.000045 & 0.000016 & 0.000020 & 0.000018 & 0.000015 \\ 0.000015 & 0.000016 & 0.000039 & 0.000010 & 0.000012 & 0.000012 \\ 0.000015 & 0.000020 & 0.000010 & 0.000040 & 0.000014 & 0.000010 \\ 0.000020 & 0.000018 & 0.000012 & 0.000014 & 0.000035 & 0.000011 \\ 0.000017 & 0.000015 & 0.000012 & 0.000010 & 0.000011 & 0.000036\end{array}\right]$ per MW

\section{Appendix 3}

Table 19 Optimal Hydro Discharge $\left(\times 10^{4} \mathrm{~m}^{3}\right)$ for case 1 of Test System 1 of variable head hydrothermal system

\begin{tabular}{|c|c|c|c|c|c|c|c|c|c|c|}
\hline Hour & $Q_{h 1}$ & $Q_{h 2}$ & $Q_{h 3}$ & $Q_{h 4}$ & 12 & 80.1994 & 71.5905 & 39.5975 & 282.2694 & 1836.34 \\
\hline 1 & 8.7861 & 6.0009 & 30.0000 & 6.0000 & 13 & 79.6781 & 72.1369 & 38.3010 & 281.2003 & 1758.68 \\
\hline 2 & 8.6477 & 6.0001 & 18.5747 & 6.0000 & 14 & 79.2573 & 72.8195 & 38.1722 & 282.2342 & 1727.52 \\
\hline 3 & 8.5682 & 6.0000 & 29.9998 & 6.0000 & 15 & 79.5884 & 73.6734 & 35.5391 & 286.6439 & 1654.55 \\
\hline 4 & 8.3775 & 6.0006 & 17.3534 & 6.0008 & 16 & 78.9796 & 75.6289 & 36.7765 & 284.1818 & 1594.43 \\
\hline 5 & 8.1550 & 6.0000 & 15.4229 & 6.0005 & 17 & 78.8516 & 76.9618 & 41.8592 & 288.8606 & 1643.46 \\
\hline 6 & 8.0533 & 6.0030 & 15.9130 & 7.9993 & 18 & 77.9593 & 78.3512 & 45.1334 & 291.6388 & 1646.92 \\
\hline 7 & 8.1591 & 6.0910 & 15.9792 & 11.1179 & 19 & 77.8291 & 79.6915 & 48.4354 & 298.8079 & 1735.23 \\
\hline 8 & 8.4589 & 6.8847 & 16.5977 & 13.6690 & 20 & 77.0919 & 80.4924 & 50.2710 & 303.4720 & 1768.67 \\
\hline 9 & 8.6193 & 7.4527 & 16.4652 & 15.3635 & 21 & 75.8005 & 81.3147 & 51.4605 & 304.7025 & 1726.72 \\
\hline 10 & 8.7715 & 7.6903 & 16.5940 & 16.1257 & 22 & 74.1001 & 81.9619 & 53.9109 & 301.5554 & 1608.47 \\
\hline 11 & 8.5801 & 7.7683 & 17.1467 & 15.7670 & 23 & 71.1238 & 82.8437 & 56.0420 & 297.2275 & 1342.77 \\
\hline 12 & 8.6525 & 8.1049 & 16.8463 & 16.5977 & 24 & 69.4655 & 81.8843 & 57.7491 & 291.3201 & 1089.58 \\
\hline
\end{tabular}
System 1 of variable head hydrothermal system (Continued)

\begin{tabular}{lllll}
\hline 13 & 8.5011 & 8.2039 & 17.4470 & 16.4653 \\
14 & 8.3269 & 8.3350 & 17.8223 & 16.5934 \\
15 & 8.2464 & 8.4235 & 18.7109 & 17.1544 \\
16 & 8.0697 & 8.7110 & 18.4832 & 16.8390 \\
17 & 8.0004 & 9.0106 & 16.9627 & 17.4464 \\
18 & 7.8467 & 9.4610 & 15.9095 & 17.8224 \\
19 & 7.8246 & 10.1045 & 14.5644 & 18.8539 \\
20 & 7.7368 & 10.6701 & 13.8283 & 19.6055 \\
21 & 7.5925 & 11.2530 & 11.0169 & 19.9997 \\
22 & 7.3682 & 11.7971 & 11.5735 & 19.9999 \\
23 & 6.9536 & 12.6091 & 12.0326 & 19.9999 \\
24 & 6.7040 & 13.4245 & 12.5674 & 19.9998 \\
\hline
\end{tabular}
test system 1 of variable head hydrothermal system

\begin{tabular}{|c|c|c|c|c|c|}
\hline Hour & $P_{h 1}$ & $P_{h 2}$ & $P_{h 3}$ & $P_{h 4}$ & $P_{s}$ \\
\hline 1 & 79.7973 & 49.0061 & 0 & 131.8801 & 1109.32 \\
\hline 2 & 79.3927 & 50.1639 & 43.5292 & 129.0270 & 1087.89 \\
\hline 3 & 79.0387 & 51.2957 & 0 & 125.7437 & 1103.92 \\
\hline 4 & 77.7373 & 52.9380 & 37.4242 & 121.6365 & 1000.26 \\
\hline 5 & 75.9674 & 54.4995 & 42.2628 & 115.8283 & 1001.44 \\
\hline 6 & 74.6619 & 55.5248 & 42.0011 & 163.8960 & 1073.92 \\
\hline 7 & 74.9610 & 56.6535 & 42.7802 & 209.7731 & 1265.83 \\
\hline 8 & 76.6787 & 62.1650 & 41.6644 & 252.8746 & 1566.62 \\
\hline 9 & 77.7838 & 65.9683 & 41.8104 & 271.8340 & 1782.60 \\
\hline 10 & 79.1114 & 67.7564 & 40.9661 & 278.4111 & 1853.75 \\
\hline 11 & 78.7489 & 68.9033 & 38.9557 & 275.1930 & 1768.19 \\
\hline 12 & 80.1994 & 71.5905 & 39.5975 & 282.2694 & 1836.34 \\
\hline 13 & 79.6781 & 72.1369 & 38.3010 & 281.2003 & 1758.68 \\
\hline 14 & 79.2573 & 72.8195 & 38.1722 & 282.2342 & 1727.52 \\
\hline 15 & 79.5884 & 73.6734 & 35.5391 & 286.6439 & 1654.55 \\
\hline 16 & 78.9796 & 75.6289 & 36.7765 & 284.1818 & 1594.43 \\
\hline 17 & 78.8516 & 76.9618 & 41.8592 & 288.8606 & 1643.46 \\
\hline 18 & 77.9593 & 78.3512 & 45.1334 & 291.6388 & 1646.92 \\
\hline 19 & 77.8291 & 79.6915 & 48.4354 & 298.8079 & 1735.23 \\
\hline 20 & 77.0919 & 80.4924 & 50.2710 & 303.4720 & 1768.67 \\
\hline 21 & 75.8005 & 81.3147 & 51.4605 & 304.7025 & 1726.72 \\
\hline 22 & 74.1001 & 81.9619 & 53.9109 & 301.5554 & 1608.47 \\
\hline 23 & 71.1238 & 82.8437 & 56.0420 & 297.2275 & 1342.77 \\
\hline 24 & 69.4655 & 81.8843 & 57.7491 & 291.3201 & 1089.58 \\
\hline
\end{tabular}

Table 19 Optimal Hydro Discharge $\left(\times 10^{4} \mathrm{~m}^{3}\right)$ for case 1 of Test

Table 20 Optimal Hydrothermal generation (MW) for case 1 of 
Table 21 Optimal Hydro Discharge $\left(\times 10^{4} \mathrm{~m}^{3}\right)$ for case 2 of test system 1 of variable head hydrothermal system

\begin{tabular}{|c|c|c|c|c|}
\hline Hour & $Q_{h 1}$ & $Q_{h 2}$ & $Q_{h 3}$ & $Q_{h 4}$ \\
\hline 1 & 10.1845 & 6.1121 & 20.5536 & 6.3438 \\
\hline 2 & 9.3545 & 6.0000 & 29.9857 & 6.0059 \\
\hline 3 & 5.0934 & 6.0672 & 18.8188 & 6.0081 \\
\hline 4 & 12.3025 & 6.9922 & 19.7814 & 6.0011 \\
\hline 5 & 9.4396 & 6.9832 & 15.2970 & 6.3376 \\
\hline 6 & 7.8835 & 6.3622 & 18.4255 & 11.1545 \\
\hline 7 & 10.2721 & 8.2105 & 18.0212 & 8.7499 \\
\hline 8 & 6.7694 & 6.0283 & 17.9212 & 9.3215 \\
\hline 9 & 6.6014 & 6.9949 & 16.6465 & 15.9994 \\
\hline 10 & 9.8394 & 6.6298 & 14.1732 & 14.6373 \\
\hline 11 & 5.8365 & 8.0881 & 17.9684 & 19.8695 \\
\hline 12 & 6.2467 & 6.7252 & 18.3894 & 15.9965 \\
\hline 13 & 10.4311 & 6.0065 & 16.4035 & 15.9976 \\
\hline 14 & 6.7118 & 6.0342 & 19.8262 & 13.0358 \\
\hline 15 & 5.2117 & 8.9019 & 14.7661 & 19.6512 \\
\hline 16 & 5.8669 & 8.0785 & 18.5218 & 18.0045 \\
\hline 17 & 10.3436 & 13.0473 & 15.8221 & 18.0241 \\
\hline 18 & 9.0289 & 8.2601 & 15.6486 & 18.1861 \\
\hline 19 & 6.8068 & 10.6257 & 18.4059 & 18.1376 \\
\hline 20 & 5.0351 & 13.1212 & 10.7805 & 18.6221 \\
\hline 21 & 7.2673 & 9.9088 & 11.9574 & 18.0174 \\
\hline 22 & 7.0480 & 12.8178 & 11.9622 & 20.0000 \\
\hline 23 & 7.9655 & 10.0050 & 10.1140 & 19.8378 \\
\hline 24 & 13.2600 & 13.2228 & 11.6386 & 19.6248 \\
\hline
\end{tabular}

Table 22 Optimal Hydrothermal generation (MW) for case 2 of test system 1 of variable head hydrothermal system

\begin{tabular}{lllllll}
\hline Hour & $P_{h 1}$ & $P_{h 2}$ & $P_{h 3}$ & $P_{h 4}$ & \multicolumn{1}{l}{$P_{s}$} & 12 \\
\cline { 1 - 4 } 1 & 86.8344 & 49.7921 & 42.4872 & 136.4915 & 1054.39 & 13 \\
2 & 82.7927 & 50.0996 & 0 & 128.7959 & 1128.31 & 14 \\
3 & 53.2023 & 51.7131 & 38.2060 & 125.5285 & 1091.35 & 15 \\
4 & 95.3572 & 59.6889 & 32.3296 & 121.2998 & 981.32 & 16 \\
5 & 82.2469 & 60.718 & 45.8186 & 119.8371 & 981.38 & 17 \\
6 & 72.3219 & 57.0068 & 36.5382 & 189.8853 & 1054.25 & 18 \\
7 & 84.3272 & 69.3217 & 39.5418 & 180.8054 & 1276.01 & 19 \\
8 & 63.8671 & 53.8113 & 40.4187 & 196.2406 & 1645.66 & 20 \\
9 & 63.4079 & 61.0171 & 43.8752 & 273.675 & 1798.02 & 21 \\
10 & 83.8010 & 59.0764 & 48.8933 & 261.1712 & 1867.06 & 22 \\
11 & 58.8915 & 69.7213 & 40.9075 & 304.3079 & 1756.17 & 23 \\
12 & 63.6159 & 61.3895 & 37.7617 & 274.8044 & 1872.42 & 24
\end{tabular}

Table 22 Optimal Hydrothermal generation (MW) for case 2 of test system 1 of variable head hydrothermal system (Continued)

\begin{tabular}{llllll}
\hline 13 & 90.3650 & 56.9064 & 44.1043 & 276.5894 & 1762.03 \\
14 & 68.1055 & 58.0340 & 32.0219 & 249.5939 & 1792.24 \\
15 & 56.4505 & 78.0365 & 46.5805 & 292.2578 & 1603.17 \\
17 & 93.8183 & 96.3354 & 45.1644 & 292.7708 & 1601.91 \\
18 & 86.3257 & 71.3305 & 44.6121 & 292.334 & 1645.39 \\
19 & 70.6874 & 82.4647 & 36.9713 & 293.5957 & 1756.28 \\
20 & 55.3803 & 89.5719 & 48.3725 & 293.5926 & 1793.08 \\
21 & 74.3523 & 73.9104 & 52.4342 & 289.3438 & 1749.96 \\
22 & 72.6529 & 84.7098 & 53.7410 & 299.7932 & 1609.10 \\
23 & 79.4951 & 71.3102 & 53.2242 & 294.2187 & 1351.75 \\
24 & 104.9608 & 81.7733 & 57.2461 & 291.4408 & 1054.58 \\
\hline
\end{tabular}

Table 23 Optimal Hydro Discharge $\left(\times 10^{4} \mathrm{~m}^{3}\right)$ of test system 2 of variable head hydrothermal system

\begin{tabular}{|c|c|c|c|c|}
\hline Hour & $Q_{h 1}$ & $Q_{h 2}$ & $Q_{h 3}$ & $Q_{h 4}$ \\
\hline 1 & 5.0000 & 8.1694 & 29.9825 & 10.6846 \\
\hline 2 & 11.8249 & 6.0349 & 20.3834 & 8.1109 \\
\hline 3 & 8.2756 & 9.3968 & 29.9993 & 6.0699 \\
\hline 4 & 10.6764 & 7.1839 & 17.4356 & 6.5270 \\
\hline 5 & 10.7913 & 6.1217 & 14.9166 & 7.0655 \\
\hline 6 & 7.5122 & 6.0114 & 19.9168 & 12.2241 \\
\hline 7 & 11.8929 & 7.1014 & 16.4236 & 14.2319 \\
\hline 8 & 8.0364 & 8.9342 & 19.9639 & 6.3860 \\
\hline 9 & 5.0000 & 7.0265 & 17.2913 & 14.8253 \\
\hline 10 & 5.2012 & 6.0000 & 19.6801 & 13.3341 \\
\hline 11 & 9.0382 & 7.4124 & 16.8647 & 18.8811 \\
\hline 12 & 7.1895 & 6.0830 & 16.7021 & 17.6400 \\
\hline 13 & 10.7560 & 8.4874 & 17.0601 & 18.0055 \\
\hline 14 & 9.6444 & 9.6666 & 16.3546 & 18.8809 \\
\hline 15 & 7.5333 & 10.1478 & 14.5476 & 16.8217 \\
\hline 16 & 12.2331 & 9.0725 & 12.3182 & 19.4624 \\
\hline 17 & 5.0001 & 9.8397 & 14.7639 & 16.0024 \\
\hline 18 & 6.9996 & 10.8825 & 13.7793 & 20.0000 \\
\hline 19 & 12.3816 & 14.8071 & 14.5850 & 20.0000 \\
\hline 20 & 5.7002 & 9.2668 & 12.3534 & 14.4891 \\
\hline 21 & 5.0013 & 6.0008 & 21.3704 & 15.8796 \\
\hline 22 & 5.0078 & 9.1880 & 11.7756 & 12.9617 \\
\hline 23 & 5.0002 & 6.0045 & 15.2021 & 13.6869 \\
\hline 24 & 9.3038 & 13.1606 & 12.9722 & 19.9519 \\
\hline
\end{tabular}


Table 24 Optimal Hydrothermal generation (MW) of test system 2 of variable head hydrothermal system

\begin{tabular}{|c|c|c|c|c|c|c|c|}
\hline Hour & $P_{h 1}$ & $P_{h 2}$ & $P_{h 3}$ & $P_{h 4}$ & $P_{s 1}$ & $P_{s 2}$ & $P_{s 3}$ \\
\hline 1 & 52.5001 & 62.9911 & 0 & 188.4124 & 20.0000 & 40.0470 & 409.0353 \\
\hline 2 & 94.9645 & 49.1472 & 36.0943 & 151.4483 & 20.0001 & 294.7080 & 139.9935 \\
\hline 3 & 77.4693 & 70.7940 & 0 & 120.2516 & 174.9999 & 40.0626 & 229.7881 \\
\hline 4 & 89.6264 & 57.8274 & 34.8294 & 121.7495 & 174.9999 & 40.0144 & 140.0427 \\
\hline 5 & 88.6817 & 51.7208 & 43.1194 & 121.7213 & 20.0713 & 209.8746 & 139.7717 \\
\hline 6 & 69.9013 & 51.9834 & 27.7926 & 202.2525 & 20.0027 & 294.7478 & 139.7384 \\
\hline 7 & 90.0410 & 59.9969 & 42.2954 & 229.2022 & 102.8131 & 294.9635 & 140.0704 \\
\hline 8 & 71.5381 & 70.3084 & 31.2740 & 155.4249 & 175.0000 & 294.7975 & 229.5029 \\
\hline 9 & 49.9772 & 57.7790 & 39.9087 & 261.0326 & 174.9942 & 294.7360 & 229.4873 \\
\hline 10 & 53.0657 & 51.3073 & 31.4504 & 247.0815 & 102.6427 & 294.7893 & 319.3190 \\
\hline 11 & 81.4462 & 62.5231 & 40.4364 & 298.9633 & 20.0014 & 294.7375 & 319.3074 \\
\hline 12 & 70.7288 & 54.3802 & 40.1454 & 287.9098 & 102.6722 & 294.7042 & 319.2878 \\
\hline 13 & 91.5678 & 70.9632 & 38.1093 & 292.8062 & 20.0158 & 294.6822 & 319.3190 \\
\hline 14 & 86.4941 & 77.0705 & 40.8922 & 298.1207 & 102.6981 & 294.7381 & 139.8472 \\
\hline 15 & 74.3655 & 79.0482 & 45.0727 & 83.9845 & 102.6488 & 294.7742 & 139.7885 \\
\hline 16 & 98.9002 & 72.9424 & 48.6283 & 302.6975 & 20.0008 & 298.7904 & 229.5013 \\
\hline 17 & 54.2296 & 76.2645 & 49.2103 & 274.8114 & 174.9981 & 294.7637 & 139.6912 \\
\hline 18 & 71.4333 & 79.2985 & 51.6777 & 304.2234 & 102.6951 & 294.7382 & 229.7389 \\
\hline 19 & 100.2199 & 87.8464 & 53.8828 & 300.4273 & 102.7774 & 294.7563 & 140.0848 \\
\hline 20 & 60.3478 & 63.3576 & 55.0328 & 254.1731 & 20.0000 & 294.7757 & 319.3300 \\
\hline 21 & 54.2311 & 42.9424 & 34.5069 & 264.0216 & 175.0000 & 40.0042 & 319.0230 \\
\hline 22 & 54.5201 & 64.1698 & 56.8181 & 236.6617 & 20.0000 & 294.7116 & 139.6709 \\
\hline 23 & 54.7321 & 44.8122 & 58.1308 & 244.4422 & 20.0024 & 294.6434 & 139.7895 \\
\hline 24 & 87.5753 & 80.9892 & 59.3598 & 292.6200 & 20.0004 & 125.0043 & 139.8794 \\
\hline
\end{tabular}

Table 25 Optimal Hydro Discharge $\left(\times 10^{4} \mathrm{~m}^{3}\right)$ of test system 3 of variable head hydrothermal system

\begin{tabular}{|c|c|c|c|c|c|c|c|c|c|}
\hline \multirow{2}{*}{$\frac{\text { Hour }}{1}$} & \multirow{2}{*}{$\begin{array}{l}Q_{h 1} \\
10.5900\end{array}$} & \multirow{2}{*}{$\begin{array}{l}Q_{h 2} \\
7.2207\end{array}$} & \multirow{2}{*}{$\frac{Q_{h 3}}{19.4370}$} & \multirow{2}{*}{$\frac{Q_{h 4}}{6.0254}$} & \multicolumn{5}{|c|}{ of variable head hydrothermal system (Continued) } \\
\hline & & & & & 13 & 11.5460 & 6.0053 & 30.0000 & 12.6269 \\
\hline 2 & 12.0523 & 7.7304 & 20.2455 & 8.5457 & 14 & 10.5001 & 10.4945 & 15.3613 & 18.1704 \\
\hline 3 & 5.0001 & 6.0184 & 17.4557 & 6.0000 & 15 & 6.9555 & 10.5776 & 10.0003 & 17.1377 \\
\hline 4 & 6.4478 & 6.3207 & 22.6585 & 14.8061 & 16 & 5.0000 & 10.6310 & 21.2541 & 19.9868 \\
\hline 5 & 5.0000 & 11.1350 & 29.9287 & 7.6698 & 17 & 10.5398 & 9.0909 & 11.1185 & 19.9873 \\
\hline 6 & 7.6269 & 9.9408 & 17.6070 & 10.8973 & 18 & 5.1753 & 6.0028 & 19.1245 & 15.2733 \\
\hline 7 & 9.2146 & 9.5815 & 13.9492 & 12.4732 & 19 & 5.0000 & 6.0000 & 18.4536 & 19.9871 \\
\hline 8 & 7.1216 & 6.0000 & 21.4589 & 6.0044 & 20 & 5.8448 & 6.0003 & 10.0100 & 19.2115 \\
\hline 9 & 14.7220 & 9.4742 & 16.3758 & 16.8335 & 21 & 6.0854 & 9.8456 & 11.2876 & 17.9333 \\
\hline 10 & 8.7003 & 6.0001 & 18.0804 & 15.0361 & 22 & 8.5236 & 11.1071 & 10.4763 & 14.4865 \\
\hline 11 & 7.6528 & 9.7120 & 10.0203 & 12.3636 & 23 & 14.9775 & 7.8296 & 13.2974 & 19.9983 \\
\hline 12 & 5.4338 & 7.2947 & 17.1649 & 16.8305 & 24 & 5.2899 & 11.9870 & 13.3435 & 18.2195 \\
\hline
\end{tabular}

Table 25 Optimal Hydro Discharge $\left(\times 10^{4} \mathrm{~m}^{3}\right)$ of test system 3 of variable head hydrothermal system (Continued) 


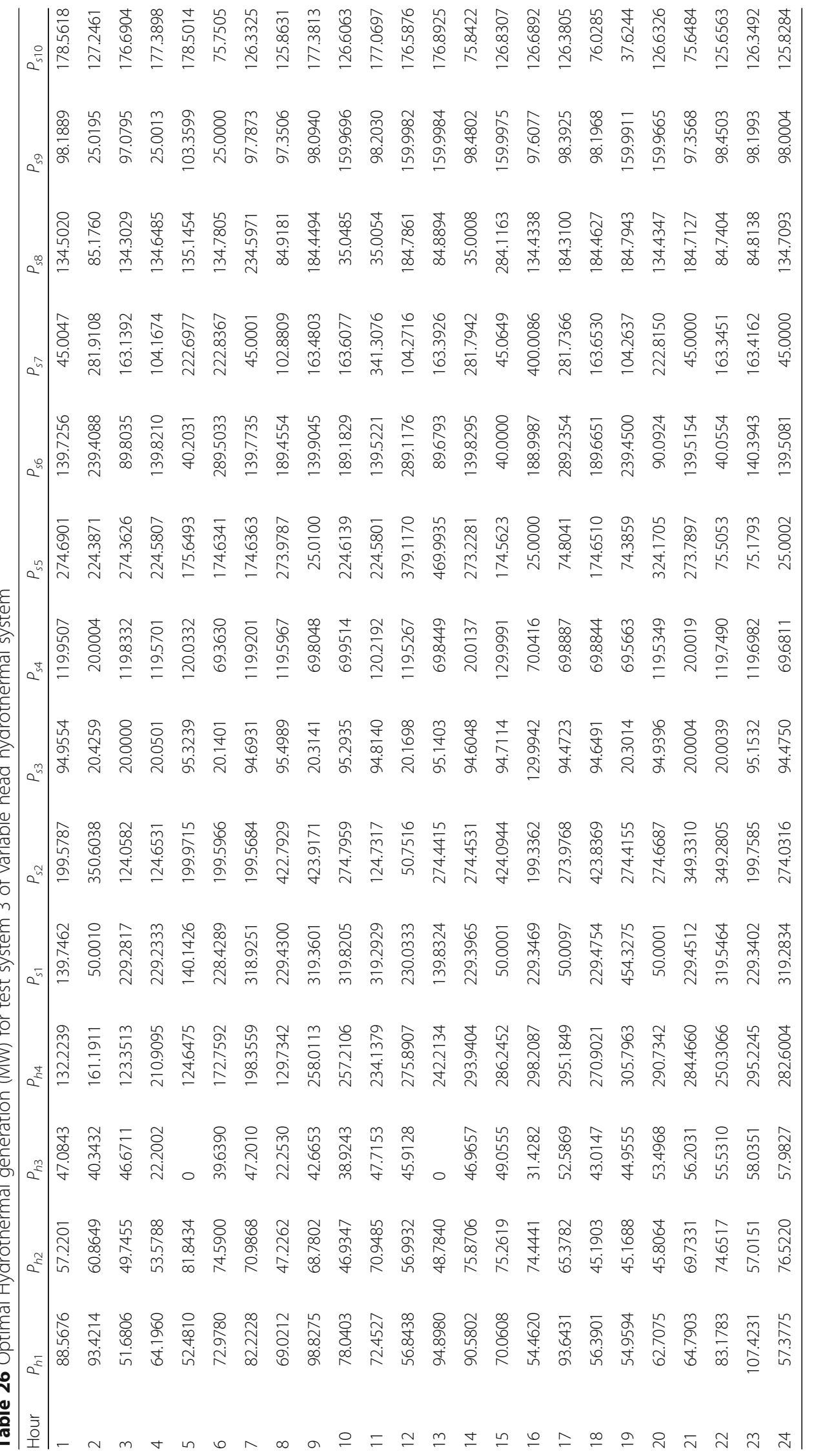




\section{Authors' contributions}

JKP makes substantial contributions to conception, design, acquisition of data, analysis and interpretation of data. JKP drafted the article and revising it thoroughly for preparation of the manuscript for the esteemed journal. Also he did the simulation part by using different test data for two different test systems. As a corresponding author he takes the primary responsibility for communication of the journal during the manuscript submission, peer review, publication process, and typically ensures that all the journal's administrative requirements, such as providing details of authorship. JKP will be available throughout the submission and peer review process to respond to editorial queries in a timely manner. Also he will be available after publication to respond to critiques of the work and cooperate with any requests from the journal for data or additional information should be answered about the paper arise after publication. JKP also agrees to be accountable for all aspects of the work in ensuring that questions related to the accuracy or integrity of any part of the work are appropriately investigated and resolved. MB participated in the peer review process of the manuscript and involved in the test data preparation. She reviewed the manuscript thoroughly. She also involved in preparation for testing of the test systems. DPD participated in the peer review process of the manuscript and to compare the performance of the proposed method with that of other evolutionary methods. He also involved in review the manuscript. All authors read and approved the final manuscript.

\begin{abstract}
Authors' information
Jagat Kishore Pattanaik has received the Master's degree in electrical engineering in 2011 from Jadavpur University, Kolkata, India. He is currently working towards the Ph.D degree in the Department of Power Engineering, Jadavpur University, Kolkata, India. His research interest are Power system and optimization techniques.

Mousumi Basu has received the Ph.D. degree from Jadavpur University, Kolkata, India. He is currently working as an Associate Professor in the Department of Power Engineering, Jadavpur University, Kolkata, India. His research interest are Power system and soft computing technique. Deba Prasad Dash has received the Ph.D. degree from Jadavpur University, Kolkata, India. He is currently working as a Professor in the Department of Electrical Engineering, Odisha Engineering College, Bhubaneswar, Odisha, India. His research interest are Power system Operation \& Control and soft computing technique.
\end{abstract}

\section{Competing interests}

The authors declare that they have no competing interests.

\section{Author details}

'Department of Power Engineering, Jadavpur University, Salt Lake City, Kolkata 700098, India. ${ }^{2}$ Electrical Engineering Department, Odisha Engineering College, Bhubaneswar, India.

Received: 26 May 2016 Accepted: 16 January 2017 Published online: 08 February 2017

\section{References}

1. Zaghlool, M. F., \& Trutt, F. C. (1988). Efficient methods for optimal scheduling of fixed head hydrothermal power systems. IEEE Transactions on Power Systems, 3, 1.

2. Nilsson, O., \& Sjelvgren, D. (1995). Mixed-integer programming applied to short-term planning of a hydro-thermal system (pp. 158-163). Salt Lake City: Proceedings of the 1995, IEEE PICA.

3. Jia, J. (2013). Mixed-integer linear programming formulation for short-term scheduling of cascaded hydroelectric plants with pumped-storage units. Electric Power Components and Systems, 41, 1456-1468.

4. Engles, L., Larson, R. E., Peschon, J., \& Stanton, K. N. (1976). Dynamic programming applied to hydro and thermal generation scheduling (IEEE tutorial course text, 76CH1107-2-PWR). New York: IEEE.

5. Wong, K. P., \& Wong, Y. W. (1994). Short-term hydrothermal scheduling part 1: simulated annealing approach. IEE Proceedings Generation Transmission and Distribution, 141(5), 497-501.

6. Yang, P. C., Yang, H. T., \& Huang, C. L. (1996). Scheduling short-term hydrothermal generation using evolutionary Programming techniques. IEE Proceedings Generation Transmission and Distribution, 143(4), 371-376.
7. Orero, O., \& Irving, M. R. (1998). A genetic algorithm modeling framework and solution technique for short term optimal hydrothermal scheduling. IEEE Trans. on PWRS, 13, 1.

8. Gil, E., Bustos, J., \& Rudnick, H. (2003). Short-term hydrothermal generation scheduling model using a genetic algorithm. IEEE Trans. on PWRS, 18(4), 1256-1264.

9. Sinha, N., Chakrabarti, R., \& Chattopadhyay, P. K. (2003). Fast evolutionary programming techniques for short-term hydrothermal scheduling. IEEE Trans. on PWRS, 18(1), 214-220.

10. Lakshminarasimman, L., \& Subramanian, S. (2006). Short-term scheduling of hydrothermal power system with cascaded reservoirs by using modified differential evolution. IEE Proceedings - Generation, Transmission and Distribution, 153(6), 693-700.

11. Yuan, X., Cao, B., Yang, B., \& Yuan, Y. (2008). Hydrothermal scheduling using chaotic hybrid differential evolution. Energy Conversion and Management, 49(12), 3627-3633.

12. Mandal, K. K., \& Chakraborty, N. (2008). Differential evolution techniquebased short-term economic generation scheduling of hydrotherma systems. Electric Power System Research, 78(11), 1972-1979.

13. Hota, P. K., Barisal, A. K., \& Chakrabarti, R. (2009). An improved PSO technique for short-term optimal hydrothermal scheduling. Electric Power System Research, 79(7), 1047-1053.

14. Basu, M. (2011). Artificial immune system for fixed head hydrothermal power system. Energy, 36, 608-612.

15. Swain, R. K., Barisal, A. K., Hota, P. K., \& Chakrabarti, R. (2011). Short-term hydrothermal scheduling using clonal selection algorithm. International Journal of Electric Power and Energy Systems, 33, 647-656.

16. Roy, P. K. (2013). Teaching learning based optimization for short-term hydrothermal scheduling problem considering valve point effect and prohibited discharge constraint. International Journal of Electric Power and Energy Systems, 53, 10-19.

17. Storn, R., \& Price, K. (1996). Minimizing the real functions of the ICEC'96 contest by differential evolution. In Proc. 1996 IEEE Int. Conf. Evolutionary Computation, ICEC'96.

18. Storn, R., \& Price, K. (1995). Differential evolution - a simple and efficient adaptive scheme for global optimization over continuous spaces, Berkeley, CA. Tech. Rep.TR-95-012.

19. Storn, R., \& Price, K. V. (1997). Differential evolution- a simple and efficient heuristic for global optimization over continuous spaces. Journal of Global Optimization, 11(4), 341-359.

20. Price, K. V., Storn, R., \& Lampinen, J. (2005). Differential evolution: a practical approach to global optimization. Berlin: Springer.

21. Tizhoosh, H. R. (2005). Opposition-based learning: a new scheme for machine intelligence. In Proc Int Conf Comput Intell Modeling Control and Autom, 1, 695-701.

22. Tizhoosh, H. R. (2005). Reinforcement learning based on actions and opposite actions. In In Proc. ICGST int conf artif intell mach learn, Cairo, Egypt.

23. Tizhoosh, H. R. (2006). Opposition-based reinforcement learning. J. Adv. Comput Intell Intelligent Inform, 10(3), 578-585.

24. Ventresca, M., \& Tizhoosh, H. R. (2006). Improving the convergence of back propagation by opposite transfer functions. In In Proc IEEE world congr. comput. intell., Vancouver, BC, Canada (pp. 9527-9534).

25. Rahnamayan, S., Tizhoosh, H. R., \& Salama, M. M. A. (2008). Oppositionbased differential evolution. IEEE Transactions on Evolutionary Computation, 12(1), 64-79.

26. Wang, H., Liu, Y., Zeng, S., Li, H., \& Li, C. (2007). Opposition-based particle swarm algorithm with Cauchy mutation. In IEEE Congress Evol. Comput. Singapore (pp. 4750-4756).

27. Malisia, A. R. (2007). Investigating the application of opposition-based ideas to ant algorithm (Master's thesis). Ontario: University of Waterloo, Waterloo.

28. Chatterjee, A., Ghoshal, S. P., \& Mukherjee, V. (2012). Solution of combined economic and emission dispatch problems of power systems by an opposition-based harmony search algorithm. International Journal of Electric Power and Energy Systems, 39, 9-20.

29. Bhattacharjee, K., Bhattacharya, A., \& Halder nee Dey, S. (2014). Oppositional real coded chemical reaction optimization for different economic dispatch problems. International Journal of Electric Power and Energy Systems, 55, 378-391.

30. Shaw, B., Mukherjee, V., \& Ghoshal, S. P. (2014). Solution of reactive power dispatch of power systems by an opposition-based gravitational 
search algorithm. International Journal of Electric Power and Energy Systems, 55, 29-40.

31. Michalewicz, Z. (1999). Genetic algorithms + data structures=evolution programs (3rd ed.). New York: Springer-Verlag Berlin Heidelberg.

32. Rashid, A. H. A., \& Nor, K. M. (1991). An efficient method for optimal scheduling of fixed head hydro and thermal plants. IEEE Transactions on Power Systems, 6(2), 632-636.

\section{Submit your manuscript to a SpringerOpen ${ }^{\circ}$ journal and benefit from:}

- Convenient online submission

- Rigorous peer review

- Immediate publication on acceptance

- Open access: articles freely available online

- High visibility within the field

- Retaining the copyright to your article

Submit your next manuscript at $>$ springeropen.com 